\title{
Characterization and Evaluation of a Folic Acid Receptor-Targeted Norcantharidin/Tetrandrine Dual-Drug Loaded Delivery System
}

\author{
Youxiang Xiong, ${ }^{1}$ Hongxia Tang, ${ }^{1}$ Wenhong Liu, ${ }^{2}$ Tingting Zhang, ${ }^{2}$ Rui Ma, ${ }^{1}$ Chaofeng Mu, ${ }^{1}$ \\ Zhihong Zhu, ${ }^{1}$ and Fanzhu Li ${ }^{1}{ }^{1}$ \\ ${ }^{1}$ School of Pharmacy, Zhejiang Chinese Medical University, Hangzhou 311400, China \\ ${ }^{2}$ School of Basic Medical Sciences, Zhejiang Chinese Medical University, Hangzhou 310053, China \\ Correspondence should be addressed to Fanzhu Li; lifanzhu@zcmu.edu.cn
}

Received 8 April 2019; Revised 5 July 2019; Accepted 16 July 2019; Published 27 August 2019

Academic Editor: Haisheng Qian

Copyright (C 2019 Youxiang Xiong et al. This is an open access article distributed under the Creative Commons Attribution License, which permits unrestricted use, distribution, and reproduction in any medium, provided the original work is properly cited.

\begin{abstract}
The objective of this study was to construct norcantharidin (NCTD)/tetrandrine (Tet) dual-drug loaded lipid nanoparticles (FA-LP@Tet/(MSNs@NCTD)) based on mesoporous silica nanoparticles (MSNs) for controlling drug release and lowering their systemic toxicity. In this study, MSNs were prepared and used for encapsulating anticancer drug NCTD; then MSNs@NCTD and Tet were loaded into liposomes to construct dual-drug loaded lipid nanoparticles with folic acid (FA) as the targeting moiety. The prepared dual-drug loaded lipid nanoparticles with a uniform particle size distribution of $153.17 \pm 4.17 \mathrm{~nm}$ (PDI $0.191 \pm 0.017$, zeta potential $-20.93 \pm 1.75 \mathrm{mV}$ ), had a visible core-shell structure under transmission electron microscopy; the encapsulation efficiency of NCTD and Tet was $86.62 \%$ and $79.19 \%$, respectively, with obvious in vitro sustained release characteristics. The cellular uptake results suggested that FA modification could enhance intracellular distribution of FA-LP@Tet/(MSNs@NCTD). Furthermore, cell apoptosis assays showed FA-LP@Tet/(MSNs@NCTD) had better antitumor ability via reversing multidrug resistance. Therefore, FA-LP@Tet/(MSNs@NCTD) was a promising drug delivery system for combination cancer therapy.
\end{abstract}

\section{Introduction}

According to Global Cancer Statistics, estimated 18.1 million new cancer cases and 9.6 million cancer-related deaths occurred in 2018 [1]. Norcantharidin (NCTD), as the anticancer agent in the world to increase white blood cells, shows a great potential in cancer treatment. NCTD, the first drug with strong antitumor properties synthesized by China, is mainly used to treat tumors in the digestive tract $[2,3]$. It possesses a broad spectrum of tumor inhibition capabilities in primary hepatic cancer [4]. However, high doses of NCTD fail to maintain an adequate blood concentration in the body owing to its short half-life. In vivo toxicities to the urinary system and drug resistance also limit its applications [5].

While chemotherapy has dominated the treatment of malignant tumors, multidrug resistance (MDR) is a main cause of chemotherapy failure [6-8]. Tetrandrine (Tet), which shows good biological activities, is the main active ingredient of tetrandra. Recent studies have shown that Tet inhibits tumor growth by reversing P-gp-mediated MDR, mitochondrial apoptosis, and exogenous apoptosis [9-12]. Moreover, Tet could combine with various drugs to reduce their toxicity while improving therapeutic efficacy [13]. Thus, Tet combination with NCTD was proposed to enhance chemotherapeutic effects.

Mesoporous silica nanoparticles (MSNs) have become the research hotspots for their unique characteristics, including their high specific surface area and excellent biocompatibility $[14,15]$. MSNs present a high loading capacity via adsorption drugs on their surfaces and in internal pores. The MSN pore can control the drug release process to achieve controlled drug release [16]. MSNs and lipid vesicles are usually dispersed in aqueous solutions, then self-assemble to form "core-shell" lipid particles (LPs) via van der Waals forces, hydrophobic and charge-related interactions. The encapsulation of lipid vesicles would prevent drug leakage 


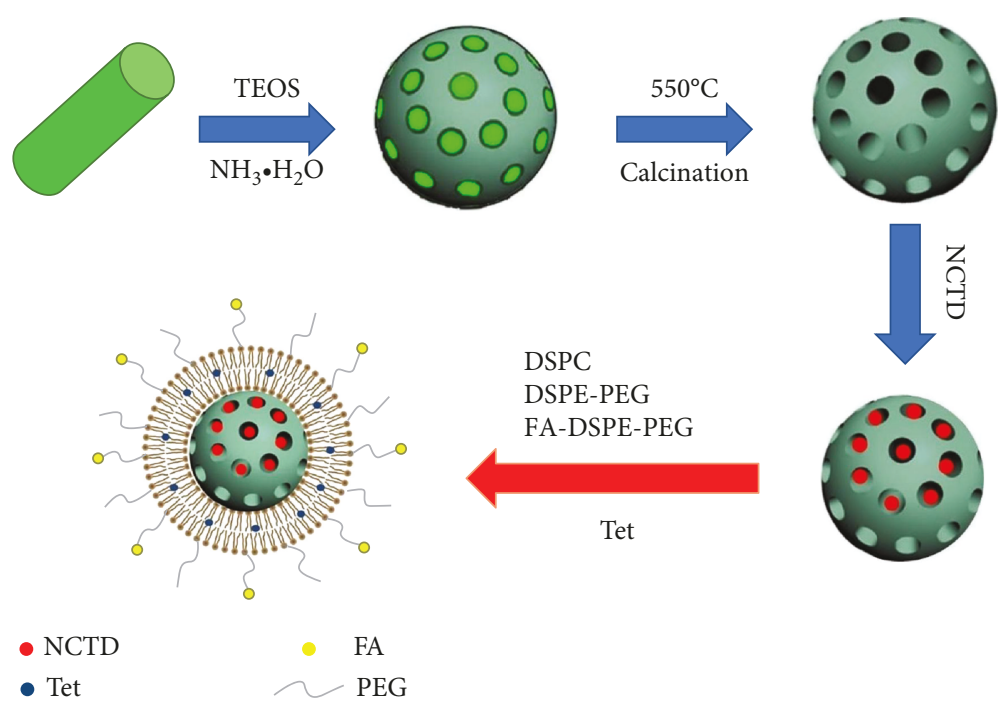

FIGURE 1: The synthetic route of FA-LP@Tet/(MSNs@NCTD).

and enhance MSN biocompatibility, which depends on the special properties of liposomes, such as long circulation in vivo, relatively nontoxic, and passive targeting $[17,18]$; LPs also exhibit strong permeability and high drug loading capability as the MSNs for core. Especially, the study on mesoporous silica lipid nanoparticle loading NCTD has never been reported previously.

Folic acid (FA), also known as vitamin B1, is a natural ligand of a folate receptor, nontoxic, weakly immunogenic, and highly biocompatible $[19,20]$. This ligand shows a good stability that could maintain high receptor affinity under long-term storage or blood circulation. Thus, FA is widely used as a targeting moiety in targeted drug delivery systems.

Herein, we reported the preparation and characterization of novel MSN-based dual-drug loaded lipid nanoparticles (Figure 1). In this work, MSNs were prepared to load the anticancer drug NCTD. Then, MSNs@NCTD and Tet were loaded into liposomes to construct dual-drug loaded lipid nanoparticles with FA as the targeting moiety. Liposomes and MSNs are easily accumulated in the liver and endocytosed by mononuclear phagocytic cells to achieve passive liver targeting, thereby causing an increased drug distribution in the liver and a decreased drug distribution in the kidney. The slow, continuous release of NCTD would enhance its therapeutic efficacy and reduce in vivo toxicity. The ability of Tet to inhibit tumor MDR also improves the antitumor effect of NCTD. In this study, we described the formulation, particle size, zeta potential, encapsulation efficiency, in vitro release, and in vitro therapeutic efficacy in tumor cells of the proposed MSN-based dual-drug loaded lipid nanoparticles.

\section{Materials and Methods}

2.1. Materials. N-Cetyltrimethylammonium bromide (CTAB), tetraethylorthosilicate (TEOS), thiazolyl blue tetrazolium bromide (MTT), fluorescein isothiocyanate (FITC), dimethyl sulfoxide (DMSO), and Hoechst 33342 were purchased from Sigma-Aldrich (USA). Ammonia
(25\%) and standard Tet (98\%) were supplied by Aladdin (Shanghai, China). Standard NCTD (100\%) was obtained from China's Food and Drug Inspection Institute. NCTD (99.16\%) and Tet (98.7\%) were obtained from Guokang Bio-technology Co. Ltd. (China). Cholesterol (CHO-HP) and 1,2-distearoyl-sn-glycero-3-phosphoethanolamine- $N$ [methoxy(polyethylene glycol)-2000] (DSPE-PEG 2000 ) were purchased from A.V.T. (Shanghai, China). 1,2-Distearoylsn-glycero-3-phosphocholine (DSPC) was obtained from Shanghai Xibao Biological Technology Co. Ltd. Folate (DSPE-PEG 2000 -FOLATE) was purchased from Nanosoft Polymers (US). DMEM/F-12 (1:1) and 0.25\% TrypsinEDTA were supplied by Gibco (US). Fetal bovine serum (FBS) was obtained from GEMINI (USA). Penicillinstreptomycin was purchased from Kino (Hangzhou, China). Methanol (chromatographic pure) was supplied by Shanghai Lingfeng Chemical Reagents Co. Ltd.

2.2. Cell Culture. Human liver cells (LO2), human hepatic carcinoma cells (HepG2), and human breast cancer cells (MCF-7) were supplied by Zhejiang Chinese Medical University (Hangzhou, China). Human drug-resistant liver cancer cells (HepG2/Adr) were purchased from Shanghai Saiqi Biological Engineering Co. Ltd. MCF-7, HepG2, LO2, and HepG2/Adr cells were cultured in DMEM supplemented with $100 \mu \mathrm{g} / \mathrm{mL}$ streptomycin, $100 \mathrm{U} / \mathrm{mL}$ penicillin, and $10 \%$ volume ratio of FBS in $5 \% \mathrm{CO}_{2}$ at $37^{\circ} \mathrm{C}$ in an incubator. The culture medium was changed every other day.

2.3. Synthesis of MSNs. MSNs were synthesized according to an optimized Stöber method. Firstly, $450 \mathrm{mg}$ CTAB was dispersed into a mixed solution (anhydrous ethanol: $45 \mathrm{~mL}$, ultrapure water: $300 \mathrm{~mL}$ ). Ammonia (25\%) was added to this mixture until $\mathrm{pH}=11.5$. The mixture was heated to $75^{\circ} \mathrm{C}$; $2.5 \mathrm{~mL}$ TEOS was added dropwise. The solution was stirred vigorously for $2 \mathrm{~h}$ and incubated for $24 \mathrm{~h}$ at $25^{\circ} \mathrm{C}$. The precipitant was collected by high centrifugation (12000 rpm, $15 \mathrm{~min}$ ) and washed twice with ultrapure water and ethyl alcohol in sequence. The sample was dried in an oven at 
$60^{\circ} \mathrm{C}$ overnight. The dried sample was calcined in a muffle furnace at $550^{\circ} \mathrm{C}$ for $6 \mathrm{~h}$ to remove the surfactant, and the final white powder was obtained as MSNs.

2.4. Preparation of MSNs@NCTD. The preparation of MSNs@NCTD referred to the method called repeated adsorption of saturated solution. Briefly, $50 \mathrm{mg}$ NCTD was dissolved in $50 \mathrm{~mL}$ ultrapure water to prepare a $1 \mathrm{mg} / \mathrm{mL}$ saturated solution. Exactly $50 \mathrm{mg}$ of dried MSNs was added to this solution, and vigorous stirring at $25^{\circ} \mathrm{C}$ for $2 \mathrm{~h}$. During stirring, the solution was sonicated for 1 min every $10 \mathrm{~min}$. The white precipitant was collected by high-speed centrifugation (15000 rpm, $30 \mathrm{~min}$ ) and washed repeatedly with ethyl alcohol. The sample was dried in an oven at $75^{\circ} \mathrm{C}$ for $2 \mathrm{~h}$ to obtain a white powder. These steps were repeated seven times to prepare the final MSNs@NCTD.

2.5. Preparation of NCTD Solution, MSN Solution, and LP@Tet/(MSNs@NCTD). NCTD solution contains NCTD (2 mg) dissolved into PBS buffer $(10 \mathrm{~mL}, \mathrm{pH} 7.4)$, and the solution was transferred to $15 \mathrm{~mL}$ centrifuge tubes.

MSN solution contains MSNs (2 mg) dispersed into PBS buffer $(10 \mathrm{~mL}, \mathrm{pH} 7.4)$, and the suspension was sonicated until a uniformly dispersed white liquid was formed; this solution was transferred to $15 \mathrm{~mL}$ centrifuge tubes.

LP@Tet/(MSNs@NCTD) was prepared with a thin-film dispersion method [21]. Briefly, DSPE-PEG 2000 (0.9 mg), DSPC $(6.3 \mathrm{mg})$, cholesterol $(2.8 \mathrm{mg})$, and Tet $(2 \mathrm{mg})$ were dissolved into a solution $(5 \mathrm{~mL}$ dichloromethane, $10 \mathrm{~mL}$ anhydrous ethanol) by sonication. The organic solvent in the solution was removed by evaporation under vacuum at $40^{\circ} \mathrm{C}$ until a thin lipid film is formed. PBS buffer $(10 \mathrm{~mL}$, pH 7.4) containing $2 \mathrm{mg}$ of MSNs@NCTD was added for hydration at $40^{\circ} \mathrm{C}$ until the formation of a dual-drug loaded liposome suspension. The obtained suspension was sonicated (power: $40 \%$; time: $4 \mathrm{~min}$ ), and a uniformly dispersed colloidal solution was obtained.

2.6. Preparation of FA-LP@Tet/(MSNs@NCTD). FALP@Tet/(MSNs@NCTD) was prepared with the thin-film dispersion method. Briefly, FA-DSPE-PEG2000 (0.18 mg), PEG2000 (0.72 mg), DSPC (6.3 mg), CHO-HP (2.8 mg), and Tet $(2 \mathrm{mg})$ were dissolved into a solution $(5 \mathrm{~mL}$ dichloromethane, $10 \mathrm{~mL}$ anhydrous ethanol) by ultrasound. Then, FA-LP@Tet/(MSNs@NCTD) was prepared by repeating the lipid encapsulation steps mentioned above.

2.7. Synthesis of FITC-Labeled Nanoparticles. MSNs (200 mg) were dispersed into $100 \mathrm{~mL}$ ethanol. Then, $0.5 \mathrm{~mL}$ ultrapure water and $0.5 \mathrm{~mL}$ APTES were added to the mixture in succession before stirring at $45^{\circ} \mathrm{C}$ for $8 \mathrm{~h}$. The prepared MSNs$\mathrm{NH}_{2}$ was collected by centrifugation (13000 rpm, $30 \mathrm{~min}$ ) and washed with ethanol thrice. Afterwards, $25 \mathrm{mg}$ MSNs$\mathrm{NH}_{2}$ was dispersed into $5.0 \mathrm{~mL}$ DMF and stirred with $1.0 \mathrm{mg}$ FITC in the dark for $12 \mathrm{~h}$ under room temperature. The FITC-labeled MSNs- $\mathrm{NH}_{2}$ (MSNs-FITC) was obtained by centrifugation (15000 rpm, $10 \mathrm{~min}$ ) and eluted with ethanol. LP-MSNs-FITC and FA-LP-MSNs-FITC were prepared by repeating the lipid encapsulation steps.
2.8. Characterizations of MSNs, MSNs@NCTD, LP@Tet/(MSNs@NCTD), and FA-LP@Tet/(MSNs@NCTD). The particle sizes, polydispersity index, and zeta potentials of MSNs, MSNs@NCTD, LP@Tet/(MSNs@NCTD), and FA-LP@Tet/(MSNs@NCTD) were measured by dynamic light scattering measurements using a Zetasizer Nano Series system (Nano-ZS90, Malvern Instruments Ltd., Malvern, United Kingdom). Morphologies of the nanoparticles were observed by transmission electron microscopy (TEM, H7650, Hitachi, Japan), and their surface areas and pore size distributions were characterized via the Barrett-JoynerHalenda and Brunauer-Emmett-Teller methods, separately. A dispersion stability test was performed by dispersing $5 \mathrm{mg} / \mathrm{mL}$ of MSNs, LP-MSNs, and FA-LP-MSNs in PBS solutions and determined the particle sizes of each nanoparticle for 14 days. Meanwhile, the Tyndall phenomenon was observed. The drug loading (DL) capabilities of NCTD and Tet were detected via HPLC using an Agilent-C18 column ( $5 \mu \mathrm{m}$ in $4.6 \times 250 \mathrm{~mm}$, Agilent, USA).

2.9. Drug Loading Amount of MSNs@NCTD. Briefly, $2 \mathrm{mg}$ MSNs@NCTD was dispersed into $5 \mathrm{~mL}$ ultrapure water and ultrasonicated for $10 \mathrm{~min}$ until all of the NCTD was released from it. The NCTD concentration in the supernatant was determined by HPLC (chromatographic column: AgilentC18 $(5 \mu \mathrm{m}$ in $4.6 \times 250 \mathrm{~mm})$; mobile phase: $0.025 \mathrm{~mol} / \mathrm{L}$; $\mathrm{KH}_{2} \mathrm{PO}_{4}$ : methanol $=85: 15$, adjusted to $\mathrm{pH} 3.0$ by the addition of phosphoric acid; flow rate: $1.0 \mathrm{~mL} / \mathrm{min}$; column temperature: $30^{\circ} \mathrm{C}$; detection volume: $20 \mathrm{~mL}$; detection wavelength: $210 \mathrm{~nm}$ ). The linear range, precision, and recovery of the methods were then evaluated.

The DL amount of MSNs@NCTD was calculated as follows:

$$
\mathrm{DL}=\frac{C_{\mathrm{NCTD}} \times V_{\text {supernatant }}}{W_{\mathrm{MSNs} @ \mathrm{NCTD}}} \times 100 \%,
$$

where $C_{\mathrm{NCTD}}$ represents the NCTD concentration in the supernatant, $V_{\text {supernatant }}$ is the volume of the supernatant, and $W_{\text {MSNs@NCTD }}$ is the theoretical amount of the MSNs@NCTD added.

2.10. Drug Entrapment Efficiency (EE) of FALP@Tet/(MSNs@NCTD). Briefly,FA-LP@Tet/(MSNs@NCTD) was ultracentrifuged $(13000 \mathrm{rpm}, 20 \mathrm{~min})$ in a TGL-16G high-speed tabletop centrifuge (Shanghai, China). The supernatant was collected; the NCTD and Tet concentrations in the supernatant were measured by HPLC. The HPLC method for detecting NCTD was identical to that described above. To detect Tet, the following HPLC conditions were applied: chromatographic column-AgilentC18 (5 $\mu \mathrm{m}$ in $4.6 \times 250 \mathrm{~mm})$; mobile phase-methano1 : ultrapure water $=80: 20$; flow rate $-1.0 \mathrm{~mL} / \mathrm{min}$; column temperature $-25^{\circ} \mathrm{C}$; detection volume- $20 \mathrm{~mL}$; and detection wavelength-282 nm. FA-LP@Tet/(MSNs@NCTD) was also sampled after demulsification, and the NCTD and Tet concentrations in the liposome were measured by HPLC. The linear range, precision, and recovery of the methods were then evaluated. 
The drug EE of FA-LP@Tet/(MSNs@NCTD) was calculated as follows:

$$
\begin{gathered}
\mathrm{EE}_{\mathrm{NCTD}}=\frac{\left(C_{\text {liposome }} \times V_{\text {liposome }}-C_{\text {supernatant }} \times V_{\text {supernatant }}\right)}{C_{\text {liposome }} \times V_{\text {liposome }}} \times 100 \%, \\
\mathrm{EE}_{\mathrm{Tet}}=\frac{\left(C_{\text {liposome }}^{\prime} \times V_{\text {liposome }}^{\prime}-C_{\text {supernatant }}^{\prime} \times V_{\text {supernatant }}^{\prime}\right)}{C_{\text {liposome }}^{\prime} \times V_{\text {liposome }}^{\prime}} \times 100 \%,
\end{gathered}
$$

where $C_{\text {liposome }}$ and $C_{\text {liposome }}^{\prime}$ represent the NCTD and Tet concentrations in the liposome, respectively; $C_{\text {supernatant }}$ and $C_{\text {supernatant }}^{\prime}$ represent the NCTD and Tet concentrations in the supernatant, separately; $V_{\text {liposome }}$ and $V_{\text {liposome }}^{\prime}$ are the volumes of the liposome; and $V_{\text {supernatant }}$ and $V_{\text {supernatant }}^{\prime}$ are the volumes of the supernatant.

2.11. In Vitro Drug Release Study. An in vitro drug release study was performed by the dialysis method. The NCTD and Tet formulations (NCTD, Tet, MSNs@NCTD, and LP@Tet/(MSNs@NCTD, 2 mL) and FA-LP@Tet/(MSNs@NCTD) were placed in a dialysis bag. The dialysis bag was placed in a beaker filled with $50 \mathrm{~mL}$ release medium containing $40 \mathrm{~mL}$ PBS and $10 \mathrm{~mL}$ ethanol at $37^{\circ} \mathrm{C}$. At predetermined sampling time points (0, 15, 30, and $45 \mathrm{~min} ; 1,2,4,6,8,12,24$, and $48 \mathrm{~h})$, $1 \mathrm{~mL}$ of the sample (each $0.5 \mathrm{~mL}$ of the sample was used to determine NCTD and Tet, separately) was withdrawn from release medium for analysis by HPLC and replaced by an equal volume of fresh medium (same temperature). All the procedures were performed for three times.

2.12. Hemolysis Test. A hemolysis test of prepared nanoparticles was carried out as a previous study [22]. In brief, $5 \mathrm{~mL}$ fresh anticoagulant blood was isolated from the ear vein of New Zealand white rabbits. Then, it was centrifuged (1500 rpm, $5 \mathrm{~min}$ ) and washed with physiological saline for 6-8 times until the supernatant became colorless. The red blood cells were diluted with physiological saline to obtain $2 \%(v / v)$ red cell suspensions. Different concentrations of MSNs, LP-MSNs, and FA-LP-MSNs were incubated with red cell suspensions for $1 \mathrm{~h}$ at $37^{\circ} \mathrm{C}$. Simultaneously, equal volumes of ultrapure water and physiological saline were selected as positive (hemolysis rate: $100 \%$ ) and negative (hemolysis rate: $0 \%$ ) controls, separately. After incubation, samples were centrifuged (1500 rpm, $10 \mathrm{~min}$ ), and the absorbance of the supernatant was measured at $414 \mathrm{~nm}$ by a microplate reader (1510, Thermo Fisher Scientific, USA). The hemolysis rates of each sample were calculated as follows:

Hemolysis rate $(\%)=\frac{\left(\mathrm{OD}_{\text {sample }}-\mathrm{OD}_{\text {negative control }}\right)}{\left(\mathrm{OD}_{\text {positive control }}-\mathrm{OD}_{\text {negative control }}\right)} \times 100 \%$.
2.13. Cellular Uptake Experiments. The cellular uptake of MSNs, LP-MSNs, and FA-LP-MSNs labeled with FITC was determined as follows [23]: HepG2 cells were cultured in six-well plates at a seeding density of $1.5 \times 10^{4}$ cells per well and incubated overnight under $37^{\circ} \mathrm{C}$. Subsequently, HepG2 cells were treated with MSNs-FITC, LP-MSNsFITC, and FA-LP-MSNs-FITC at an FITC concentration of $4 \mu \mathrm{M}$. After being cultured with the nanoparticles for $4 \mathrm{~h}$, HepG2 cells were washed thrice with PBS $(500 \mu \mathrm{L})$, fixed with $4 \%(v / v)$ paraformaldehyde for $10 \mathrm{~min}$, and then washed thrice with PBS (5 min/time). Afterwards, the cells were stained with $5 \mu \mathrm{g} / \mathrm{mL}$ DAPI for $10 \mathrm{~min}$. The stained samples were observed under a fluorescence microscope.

For flow cytometry experiment, HepG2 cells were cultured in six-well plates at $6 \times 10^{5}$ cells per well and incubated for $12 \mathrm{~h}$ at $37^{\circ} \mathrm{C}$. Next, HepG2 cells were treated with culture medium containing FITC-labeled nanoparticles (blank, MSNs-FITC, LP-MSNs-FITC, and FA-LP-MSNs-FITC, at an FITC concentration of $4 \mu \mathrm{M}$ ) for $4 \mathrm{~h}$. Afterwards, cells were washed with PBS thrice and harvested. The fluorescence intensity was measured by flow cytometry (Guava Easycyte, Merck Millipore, Darmstadt, Germany).

The amount of Tet taken up by HepG2 cells was quantitatively determined by HPLC, as described above (i.e., drug EE of FA-LP@Tet/(MSNs@NCTD)). The methodology of the method was also evaluated. Briefly, HepG2 cells were seeded into a six-well plate at a density of $1.0 \times 10^{6}$ cells per well for $12 \mathrm{~h}$. The medium was replaced with $16 \mu \mathrm{g} / \mathrm{mL}$ nanoparticles (LP@Tet/(MSNs@NCTD) and FA-LP@Tet/(MSNs@NCTD)) containing culture medium. At predetermined time points $(2,4,8$, and $16 \mathrm{~h})$, the medium was removed, and cells were collected for further determination. HepG2 cells were washed, lysed, vortexed, and ultracentrifuged [24]. The supernatant was sampled, and Tet concentrations at different time points were assayed by HPLC.

2.14. In Vitro Cytotoxicity Experiments. MTT assays were carried out to test the cytotoxicity of carriers (MSNs, LP-MSNs, and FA-LP-MSNs) and drug formulations (NCTD, LP-MSNs@NCTD, LP@Tet/(MSNs@NCTD), and FA-LP@Tet/(MSNs@NCTD)) on LO2, MCF-7, HepG2, and HepG2/Adr cells [24-27]. Briefly, $3 \times 10^{3}$ cells were plated in $100 \mu \mathrm{L}$ medium per well in a 96-well plate and incubated for $12 \mathrm{~h}$ in $5 \% \mathrm{CO}_{2}$ at $37^{\circ} \mathrm{C}$. The cells were incubated with culture medium, which contains the drug carriers or drug formulations for $48 \mathrm{~h}$. Following incubation, $20 \mu \mathrm{L}$ MTT solution $(5 \mathrm{mg} / \mathrm{mL})$ was added to each well; then the cells were incubated at $37^{\circ} \mathrm{C}$ for another $4 \mathrm{~h}$. Afterwards, the supernatant was removed, the precipitate was dissolved into $200 \mu \mathrm{L}$ DMSO, and the absorbance of the sample solution was measured at $570 \mathrm{~nm}$ with a microplate reader (Synergy TM2, BIO-TEK Instruments Inc., USA). Each concentration was determined for three times.

2.15. Cell Apoptosis Experiments. Cell apoptosis was observed by nucleus staining with DAPI. Briefly, HepG2 and HepG2/Adr cells were seeded into 24 -well plates at a density of 


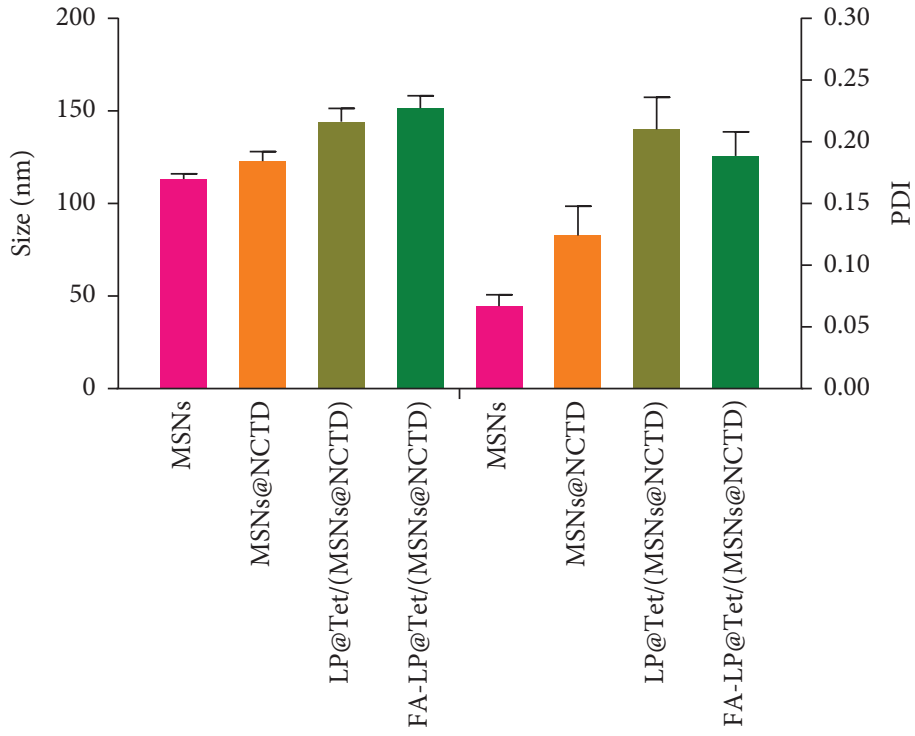

(a)

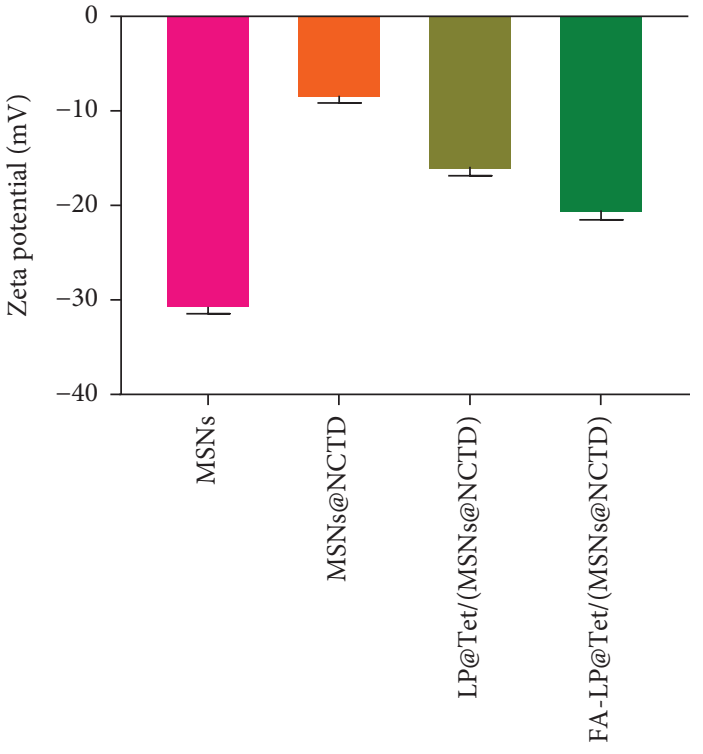

(b)

FIGUre 2: The particle size and PDI (a) and zeta potential (b) of MSNs, MSNs@NCTD, LP@Tet/(MSNs@NCTD), and FALP@Tet/(MSNs@NCTD), respectively.

$5 \times 10^{4}$ cells per well in $5 \% \mathrm{CO}_{2}$ at $37^{\circ} \mathrm{C}$. After cells adhered to the wall, Jatamanvaltrate $\mathrm{P}$ was added to the wells, followed by $500 \mu \mathrm{L}$ of drug-containing culture medium (FA-LP@Tet/(MSNs@NCTD)). The plates were then incubated for $24 \mathrm{~h}$. After the removal of the culture medium, cells were washed with $500 \mu \mathrm{L}$ of PBS, fixed with $4 \%(v / v)$ paraformaldehyde for $15 \mathrm{~min}$, washed thrice with PBS, and stained with $5 \mu \mathrm{g} / \mathrm{mL}$ DAPI at $37^{\circ} \mathrm{C}$ for $20 \mathrm{~min}$. Finally, the stained sample was observed using the fluorescence microscope.

Cell apoptosis was also detected by FACS with an annexin V-FITC/PI apoptosis-detection kit (BD, US). LO2, HepG2, and HepG2/Adr cells were analogously seeded into six-well plates at a density of $5 \times 10^{5}$ cells per well. After cells adhered, Jatamanvaltrate $\mathrm{P}$ was added, followed by $2 \mathrm{~mL}$ drug-containing culture medium (FALP@Tet/(MSNs@NCTD)). The plate was then incubated for $24 \mathrm{~h}$. The cells were washed; then pancreatin without EDTA was added to digest cells. Cell suspension solution was collected into $1.5 \mathrm{~mL}$ EP tubes. Afterwards, $500 \mu \mathrm{L}$ of $1 \mathrm{x}$ binding buffer was added to cells, and $100 \mu \mathrm{L}$ cell suspension solution was collected into new EP tubes. The cells were stained with $5 \mu \mathrm{L}$ of annexin V-FITC and $5 \mu \mathrm{L}$ of PI for $15 \mathrm{~min}$ in succession. Finally, cells were mixed with $400 \mu \mathrm{L}$ of $1 \mathrm{x}$ binding buffer and then analyzed with a BD FACSCalibur system [24].

2.16. Western Blotting Analysis. HepG2/Adr cells at the logarithmic growth phase were seeded at a density of $8 \times 10^{5}$ cells/well in $5 \% \mathrm{CO}_{2}$ at $37^{\circ} \mathrm{C}$. After adherent growth for $24 \mathrm{~h}$, the original media were removed, fresh drug-containing culture media (FA-LP@Tet/MSNs, FALP/(MSNs@NCTD), FA-LP@Tet/(MSNs@NCTD) (concentrations: 0,8 , and $16 \mu \mathrm{g} / \mathrm{mL}$ )) were added to the wells, and the cells were incubated for another $24 \mathrm{~h}$. Total proteins were extracted, and protein samples were prepared.
HepG2/Adr cells were lysed in RIPA buffer with protease inhibitors (PMSF), and a BCA kit (Takara) was used to quantitate proteins. Subsequently, SDS-PAGE gels were used to perform electrophoresis analysis.

2.17. Statistical Analysis. All data were reported as the mean \pm standard deviation. Statistical significances were analyzed by one-way analysis of variance (ANOVA) with SPSS software (SPSS 17.0, Chicago, IL, USA). Additionally, $P<0.05$ was considered statistically significant, and $P<0.01$ was considered extremely significant.

\section{Results}

3.1. Synthesis of FA-LP@Tet/(MSNs@NCTD). Firstly, we synthesized MSNs according to an optimized Stöber method. Considering the fact that NCTD could be easily released from MSNs and the biocompatibility of formulations, a lipid bilayer was employed to coat MSNs. To reverse the MDR of NCTD, Tet was loaded into the lipid bilayer. Finally, FA was modified onto the lipid bilayer to achieve active targeted drug delivery. The common lipid bilayer consisted of cholesterol, DSPC, and DSPE-PEG 2000 , and the tumor active-targeting function was implemented by anchoring FA-DSPE-PEG ${ }_{2000}$ in the lipid bilayer. The proposed synthesis route is shown in Figure 1.

\subsection{Characterization of MSNs, MSNs@NCTD,} LP@Tet/(MSNs@NCTD), and FA-LP@Tet/(MSNs@NCTD). The synthesized MSNs showed uniform size distributions and favorable dispersity, with average diameters of $114.67 \pm 1.67 \mathrm{~nm}$ and PDI of $0.069 \pm 0.007$ (Figure 2(a)). TEM images suggested that the MSNs had a spherical structure with a smooth surface (Figure 2(a)). After NCTD loading, the average diameter of MSNs@NCTD increased 


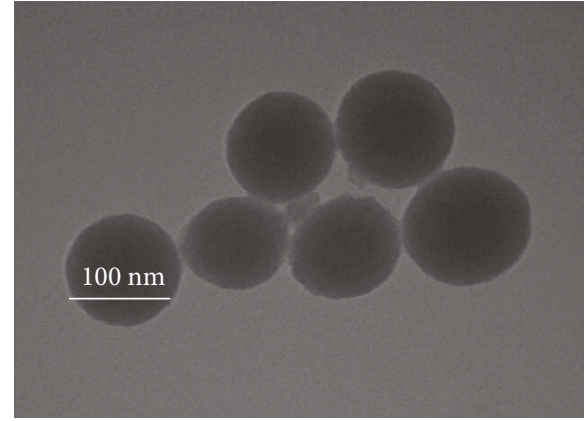

(a)

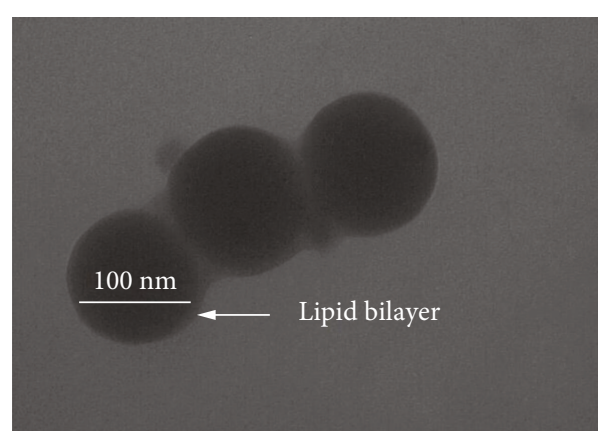

(b)

FIGURE 3: Morphology characterizations: TEM images of MSNs (a) and FA-LP-MSNs (b), respectively.

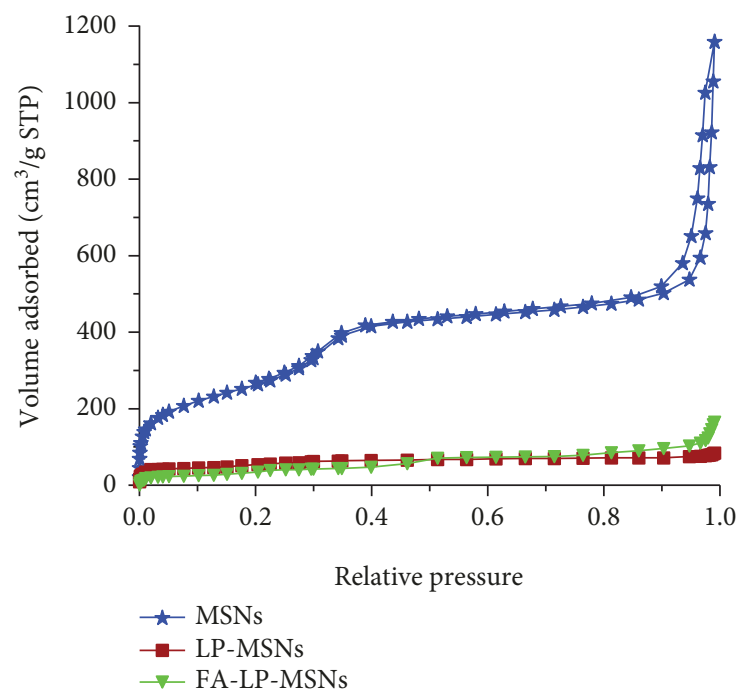

(a)

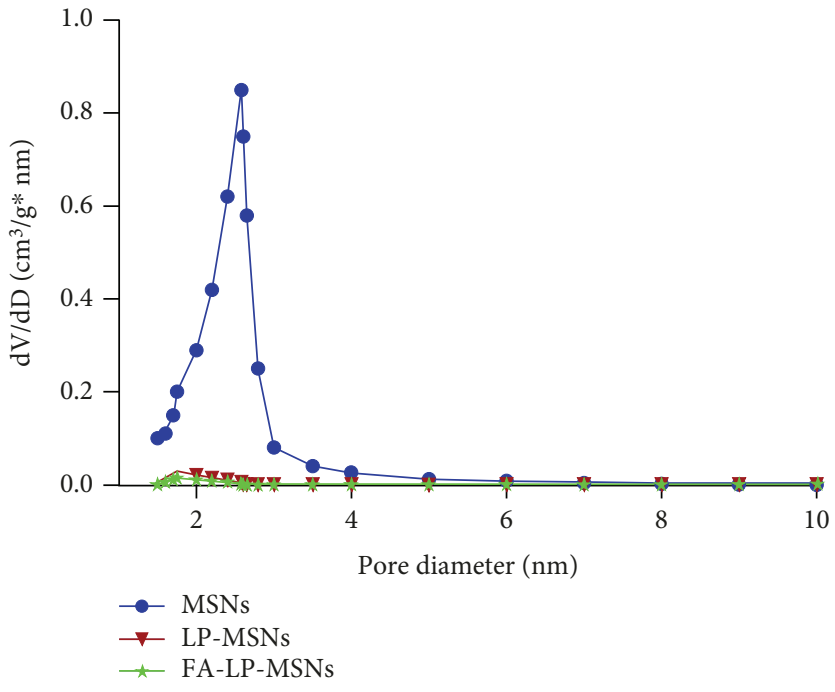

(b)

Figure 4: The $\mathrm{N}_{2}$ adsorption-desorption isotherm (a) and pore size distribution (b) of MSNs, LP-MSNs, and FA-LP-MSNs, respectively.

to $124.33 \pm 2.33 \mathrm{~nm} \quad(\mathrm{PDI}=0.130 \pm 0.016) \quad($ Figure $2(\mathrm{a})$ ), and the zeta potential increased from $-31.07 \pm 0.43 \mathrm{mV}$ for MSNs to $-8.77 \pm 0.59 \mathrm{mV}$ for MSNs@NCTD (Figure 2(b)). These results indicated that NCTD was successfully loaded into MSNs. MSNs@NCTD was coated by the lipid bilayer, and Tet was concomitantly entrapped. In this procedure, the particle size of the obtained nanoparticles, LP@Tet/(MSNs@NCTD), was 145.67 $\pm 2.67 \mathrm{~nm}$ $(\mathrm{PDI}=0.212 \pm 0.024)$ (Figure $2(\mathrm{a})$ ), and its zeta potential was $-16.43 \pm 1.37 \mathrm{mV}$ (Figure 2(b)). Finally, FA was modified on the lipid bilayer for active targeted drug delivery. The final product, FA-LP@Tet/(MSNs@ NCTD), displayed a spherical structure with a smooth surface similar to that of MSNs and had a lipid bilayer around the MSNs (Figure 3(b)). The particle size and zeta potential of FA-LP@Tet/(MSNs@NCTD) were $153.17 \pm 3.17 \mathrm{~nm}$ $(\mathrm{PDI}=0.191 \pm 0.017)$ and $-20.93 \pm 1.75 \mathrm{mV}$, respectively (Figures 2(a) and 2(b)). These results confirmed that the targeting moiety, FA, was successfully modified.

The synthesis process of different nanoparticles was characterized in terms of $\mathrm{N}_{2}$ adsorption-desorption isotherms and pore size distributions. In Figure 4, MSNs displayed a type IV isotherm reference to IUPAC classification and a mesoporous pore size of $2.58 \mathrm{~nm}$. The isotherm obtained indicated that the mesopores of MSNs were encapsulated by a lipid bilayer, which was reflected by the substantial reduction of the surface area from $1158.80 \mathrm{~m}^{2} / \mathrm{g}$ for MSNs to $85.90 \mathrm{~m}^{2} / \mathrm{g}$ for LP-MSNs (Figure $4(\mathrm{a})$ ). As the final nanoparticles were synthesized, the pore volumes and pore sizes of the products in each step gradually decreased (Figure 4).

Dispersion stability tests were performed by determining the particle size changes of MSNs, LP-MSNs, and FA-LP-MSNs in PBS, separately. In Figure 5, the MSNs aggregated and their size increased to above $300 \mathrm{~nm}$ after incubation for 14 days. However, lipid coating nanoparticles (LP-MSNs and FA-LP-MSNs) were relatively stable with obvious Tyndall phenomenon during 14 days. Therefore, the physical stability of MSNs was improved greatly after lipid capping.

3.3. Drug Loading and Drug Release of FALP@Tet/(MSNs@NCTD). The drug loading amount of MSNs@NCTD and entrapment efficiency of FALP@Tet/(MSNs@NCTD) were determined by HPLC. The 

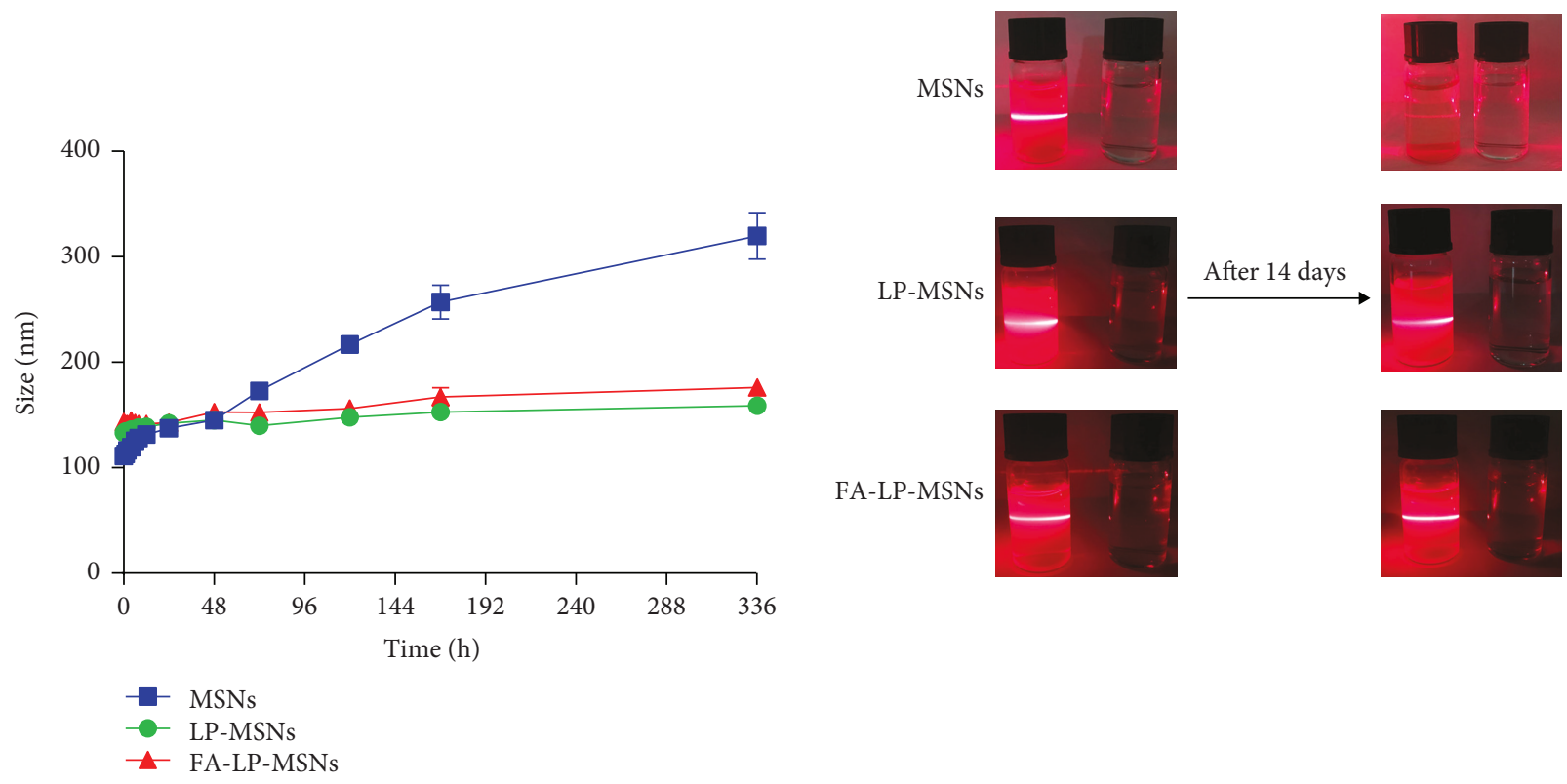

FA-LP-MSNs
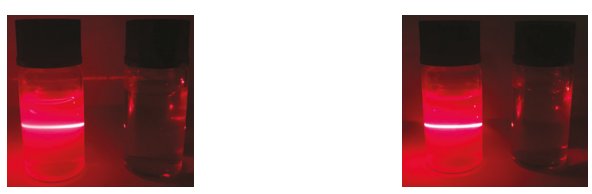

FIGURE 5: The particle sizes and Tyndall phenomenon of MSNs, LP-MSNs, and FA-LP-MSNs in PBS during 14 days.

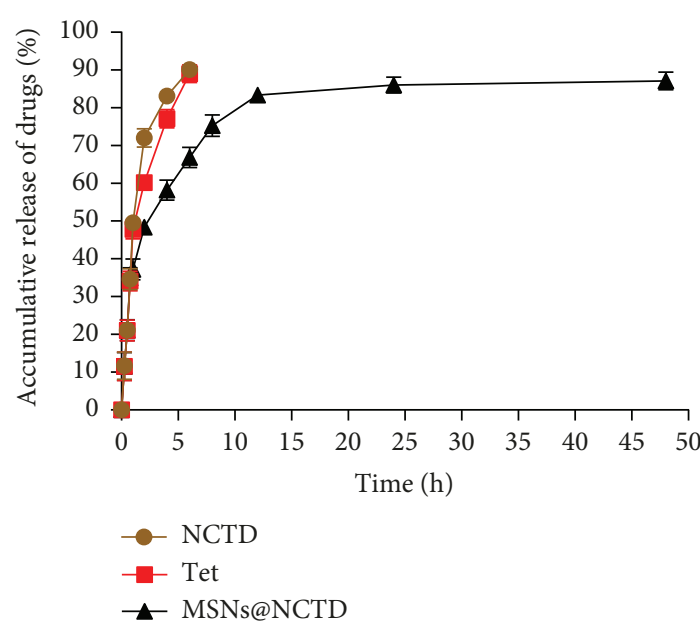

(a)

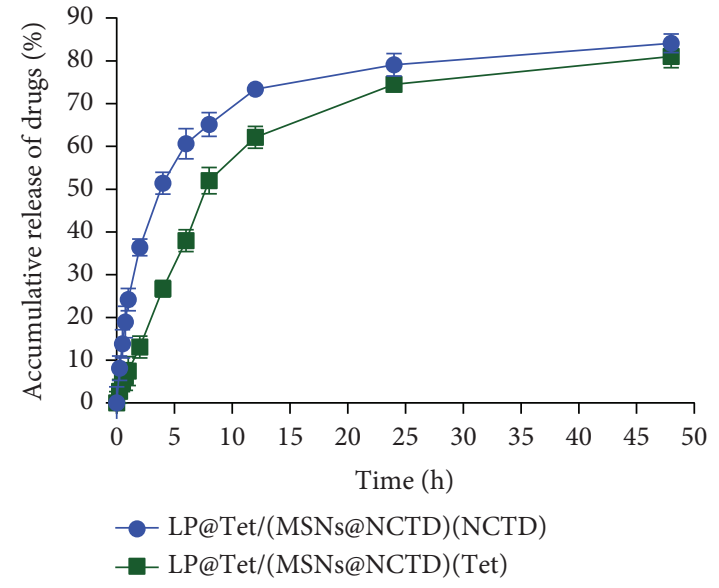

(b)

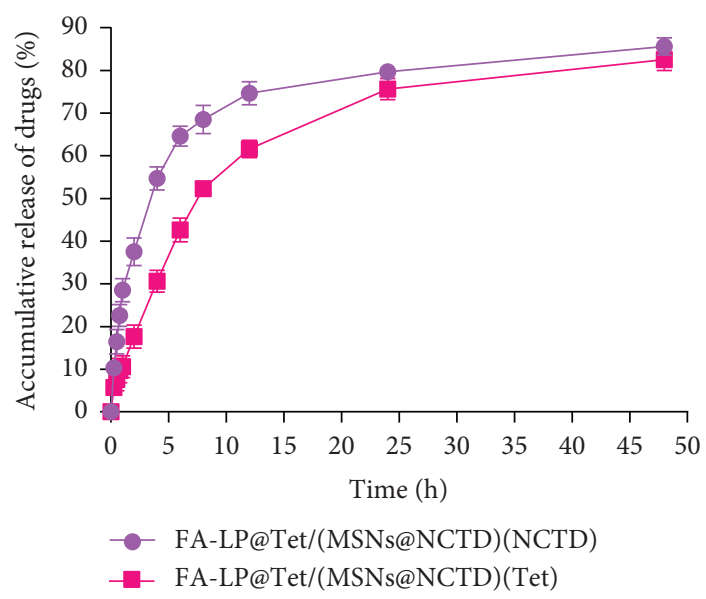

(c)

Figure 6: In vitro release of NCTD, Tet, and MSNs@NCTD (a); LP@Tet/(MSNs@NCTD) (b); and FA-LP@Tet/(MSNs@NCTD) (c) in PBS buffer (pH 7.4, containing 10\% ethanol) during $48 \mathrm{~h}(n=3)$. 


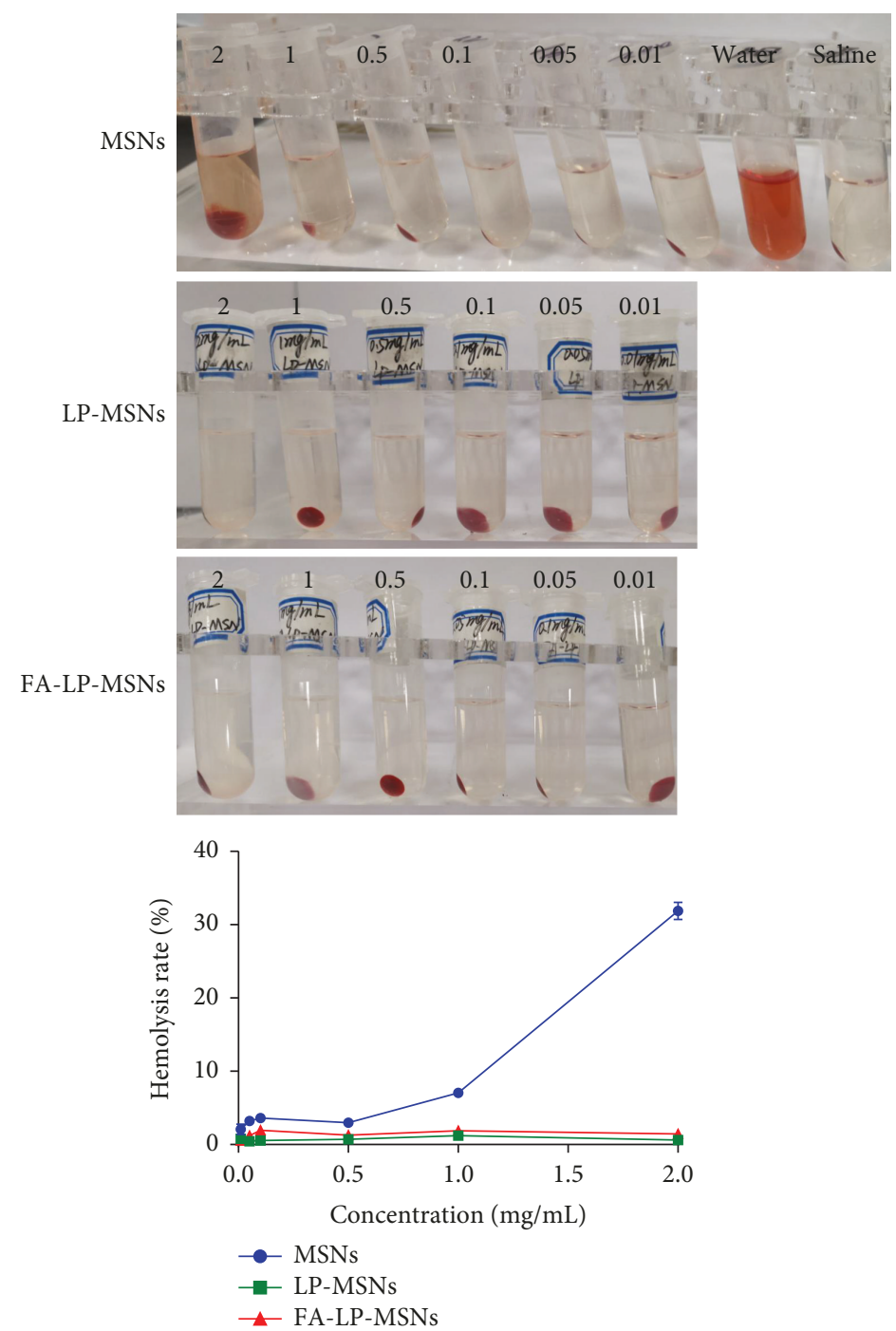

Figure 7: Hemolysis test of MSNs, LP-MSNs, and FA-LP-MSNs.

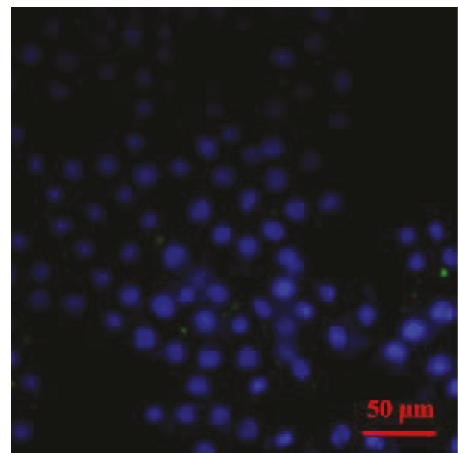

MSN-FITC

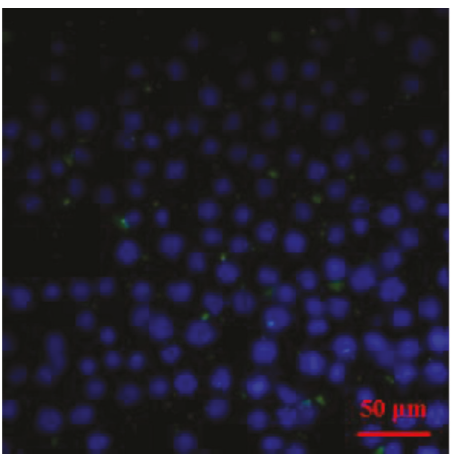

LP-MSN-FITC

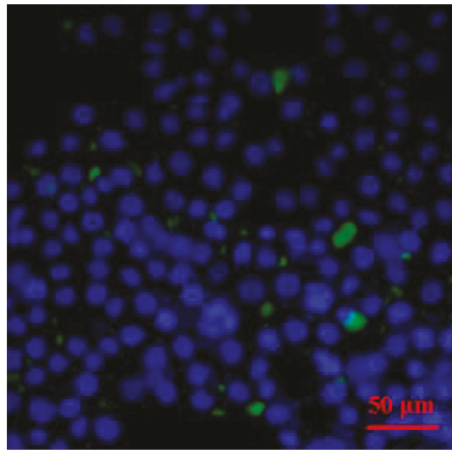

FA-LP-MSN-FITC

FIGURE 8: Fluorescence images of HepG2 cell incubation with MSNs-FITC, LP-MSNs-FITC, and FA-LP-MSNs-FITC containing medium for 4 h. Scale bar: $50 \mu \mathrm{m}$.

standard curve equations of NCTD and Tet were $Y=$ $0.6056 X-0.1248\left(R^{2}=0.9998\right)$ at a linear concentration range of $4-128 \mu \mathrm{g} / \mathrm{mL}$ and $Y=13.85 X-0.152\left(R^{2}=0.9997\right)$ at the linear concentration range of $6-40 \mu \mathrm{g} / \mathrm{mL}$, respectively.
The precision and recovery of the methods fit the requirements of specimen analysis. MSNs could load approximately 7.95\% NCTD by electrostatic interactions in their mesoporous structure. After coating with the lipid bilayer, the EEs 
of NCTD and Tet in LP@Tet/(MSNs@NCTD) increased to $86.62 \%$ and $79.19 \%$, respectively. After modification of FA on the lipid bilayer, the EEs of NCTD and Tet in LP@Tet/(MSNs@NCTD) were slightly reduced to 85.74\% and $78.36 \%$, respectively.

PBS buffer ( $\mathrm{pH} 7.4$ ) containing $10 \%$ ethanol was employed as the release medium to evaluate the controlled drug release capability of FA-LP@Tet/(MSNs@NCTD). As presented in Figure 6, the release rates of NCTD and Tet solutions were fast and complete (approximately 90\% within $6 \mathrm{~h}$ ). Compared with the NCTD and Tet solutions, the other NCTD- and Tet-loaded nanoparticles exhibited obvious controlled release characteristics. Approximately 83.34\% of NCTD was released from the MSNs within $12 \mathrm{~h}$, much faster than the recorded release rate from LP-MSNs (73.40\%). This result revealed that the lipid bilayer contributed to the controlled drug release. Compared with LP@Tet/(MSNs@NCTD), the final formulation, FA-LP@Tet/(MSNs@NCTD), displayed a slightly higher release rate, implying that the liposomes became slightly instable after modification with FA.

3.4. Hemolysis Test. A hemolysis test was performed by using the fresh blood of a rabbit. As presented in Figure 7, the hemolysis rate of unmodified MSNs was up to $32 \%$ at the concentration of $2 \mathrm{mg} / \mathrm{mL}$ after being incubated with red cells for $1 \mathrm{~h}$. Notably, the hemolysis toxicity of lipid-coated MSNs (LP-MSNs and FA-LP-MSNs) was remarkably reduced to $0.60 \%$ and $1.44 \%$, separately. The results showed that the lipid-coated MSNs could significantly decrease the toxicity of MSNs, which indicated that the modification of MSNs was necessary.

3.5. Cellular Uptake and Intracellular Distributions. HepG2 cells were cultured with different FITC-labeled nanoparticles (MSNs-FITC, LP-MSNs-FITC, and FA-LP-MSNs-FITC) to investigate the cellular endocytosis and subcellular localization of the nanoparticles. Three groups of HepG2 cells were observed with a fluorescence microscope after $4 \mathrm{~h}$ incubation. In Figure 8, the LP-MSNs-FITC and FALP-MSNs-FITC exhibited strong fluorescence signals, whereas those of MSNs-FITC were weak, which revealed that the lipid encapsulation nanoparticles were internalized by endocytosis. Moreover, compared with the fluorescence intensity of LP-MSNs-FITC, that of FA-LP-MSNs-FITC was much higher, which suggests that modification of FA significantly improves the endocytosis of FA-LP-MSNs-FITC via its binding with the folic acid receptors on a tumor cell membrane.

The targeting ability of carriers on HepG2 cells was also measured by flow cytometry. As shown in Figure 9, after $4 \mathrm{~h}$ incubation with HepG2 cells, the average fluorescence intensity of all groups could be ordered as follows: FA - LP - MSNs - FITC > LP - MSNs - FITC > MSNs - FITC, because lipid coating could improve the affinity between carriers with the cell membrane, thereby promoting the cellular uptake in some degree. Additionally, the modification of FA could further improve the endocytosis of carriers with its targeting role to tumor cells.

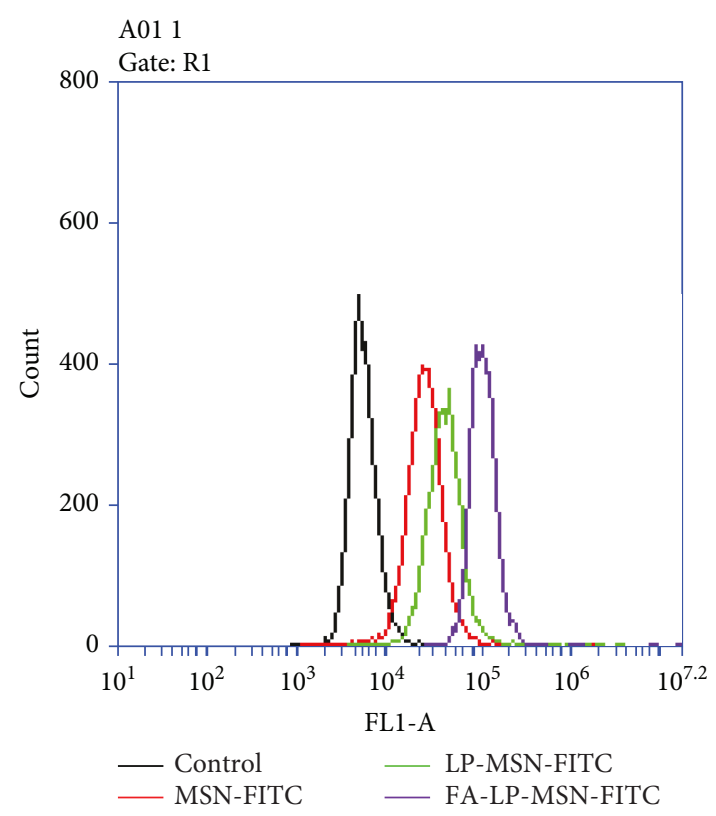

FIgURe 9: Flow cytometry profiles of HepG2 cell incubation with MSNs-FITC, LP-MSNs-FITC, and FA-LP-MSNs-FITC containing medium for $4 \mathrm{~h}$.

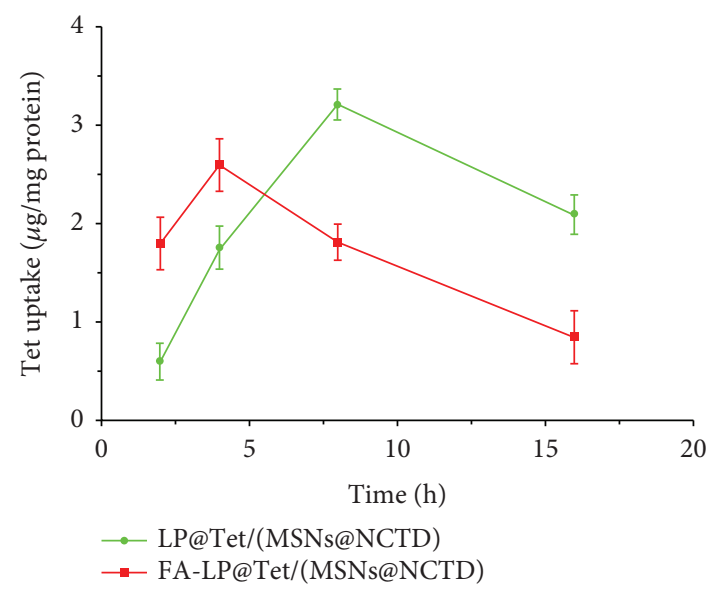

FIgURE 10: The cellular uptake amount of Tet in the HepG2 cells at different times $(n=3)$.

The amount of Tet taken up by HepG2 cells was measured by HPLC as mentioned above (i.e., drug EE of FALP@Tet/(MSNs@NCTD)). The standard curve of Tet was $Y=11.267 X-1.2246\left(R^{2}=0.9990\right)$ at a linear concentration range of $0.5-8 \mu \mathrm{g} / \mathrm{mL}$. The precision and recovery of the method fit the requirements of the biological specimen analysis. Figure 10 displays the amount of Tet uptake in HepG2 cells at different times after being treated with LP@Tet/(MSNs@NCTD) and FA-LP@Tet/(MSNs@NCTD). The drug content in cells initially increased with treatment time. FA-LP@Tet/(MSNs@NCTD) showed higher uptake by the HepG2 cells at earlier stages than LP@Tet/(MSNs@NCTD). However, the amount of Tet in HepG2 cells showed a downward trend after incubation with FA-LP@Tet/(MSNs@ NCTD) for 4h, which was earlier than that incubated with LP@Tet/(MSNs@NCTD). 

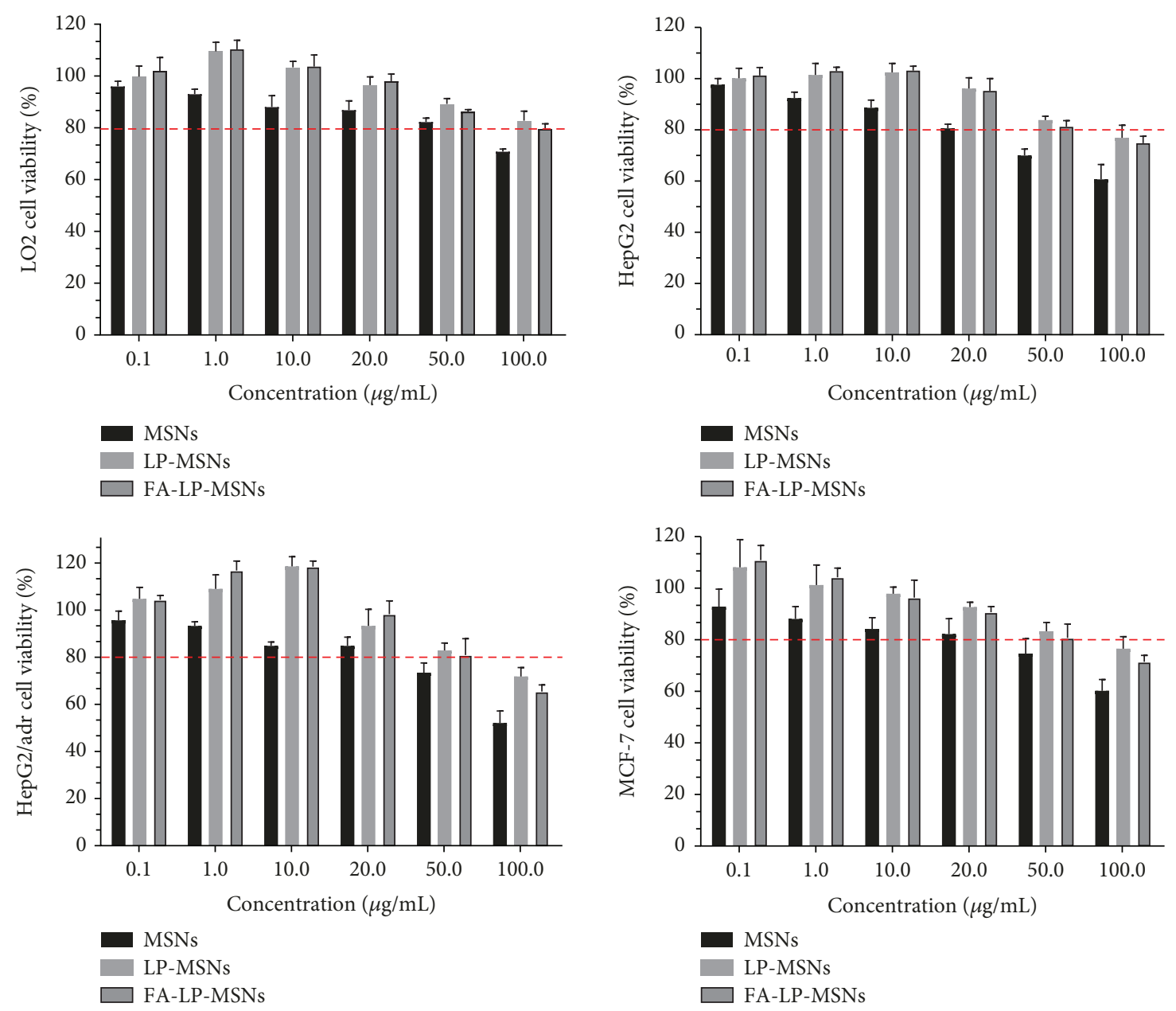

Figure 11: MTT assay of LO2, HepG2, HepG2/Adr, and MCF-7 cells after being treated with culture medium containing MSNs, LP-MSNs, and FA-LP-MSNs at the concentrations from $0.1 \mu \mathrm{g} / \mathrm{mL}$ to $100 \mu \mathrm{g} / \mathrm{mL}$ for $48 \mathrm{~h}(n=3)$.

3.6. Cytotoxicity of FA-LP@Tet/(MSNs@NCTD). The drug carriers (MSNs, LP-MSNs, and FA-LP-MSNs) were incubated with LO2, HepG2, HepG2/Adr, and MCF-7 cells for $48 \mathrm{~h}$ to assess the cytotoxicity of the functionalized nanoparticles. Figure 11 shows that over $80 \%$ of cells survived when the concentration of the drug carriers was below $20 \mu \mathrm{g} / \mathrm{mL}$. This result revealed that all drug carriers exhibited excellent biocompatibility. Compared with LPMSNs and FA-LP-MSNs, MSNs showed higher cytotoxicity, which indicated that lipid coating could markedly reduce toxicity.

LO2, HepG2, HepG2/Adr, and MCF-7 cells were incubated with NCTD, LP-MSNs@NCTD, LP@Tet/(MSNs@NCTD), and FA-LP@Tet/(MSNs@NCTD) for 48h to determine the cytotoxicity of drug-containing nanoparticles. As presented in Figure 12, with increasing NCTD concentration, the cell viability decreased; with the improvement of the formulations, the inhibition effect also increased. In Figure 13, the $\mathrm{IC}_{50}$ values of NCTD against HepG2, HepG2/Adr, MCF-7, and LO2 cells were $13.677 \pm 0.982$ $\mu \mathrm{g} / \mathrm{mL}, 16.280 \pm 0.863 \mu \mathrm{g} / \mathrm{mL}, 19.329 \pm 1.297 \mu \mathrm{g} / \mathrm{mL}$, and $49.369 \pm 1.835 \mu \mathrm{g} / \mathrm{mL}$, respectively. These results suggested that NCTD had better cytotoxicity against HepG2, Hep-
G2/Adr, and MCF-7 cells compared with LO2 cells. LO2 cells showed high survival rates $(75 \%-85 \%)$ at the $\mathrm{IC}_{50}$ of tumor cells induced by the above nanoparticles. Moreover, the final formulation,FA-LP@Tet/(MSNs@NCTD), exhibited the best antitumor efficiency compared with other formulations, especially in HepG2/Adr cells. In summary, the prepared formulations were appropriate to treat hepatic carcinoma with good biocompatibility.

3.7.FA-LP@Tet/(MSNs@NCTD) Induced Cell Apoptosis. HepG2 and HepG2/Adr cells were treated with FALP@Tet/(MSNs@NCTD) at the concentrations from $0 \mu \mathrm{g} / \mathrm{mL}$ to $16 \mu \mathrm{g} / \mathrm{mL}$ for $24 \mathrm{~h}$, stained with DAPI, and observed using a fluorescence microscope. In Figure 14, concentration-dependent apoptotic body formation and nuclear fragmentation could be easily found in treatment groups ( 8 and $16 \mu \mathrm{g} / \mathrm{mL}$ ). An integrated nucleus was observed in the control group $(0 \mu \mathrm{g} / \mathrm{mL})$, which indicated that FA-LP@Tet/(MSNs@NCTD) could induce apoptosis of cancer cells (HepG2, HepG2/Adr cells). Compared with the nuclear fragmentation in HepG2 cells, more extensive nuclear fragmentation was observed in HepG2/Adr cells (treatment groups), thus confirming the initial finding that 

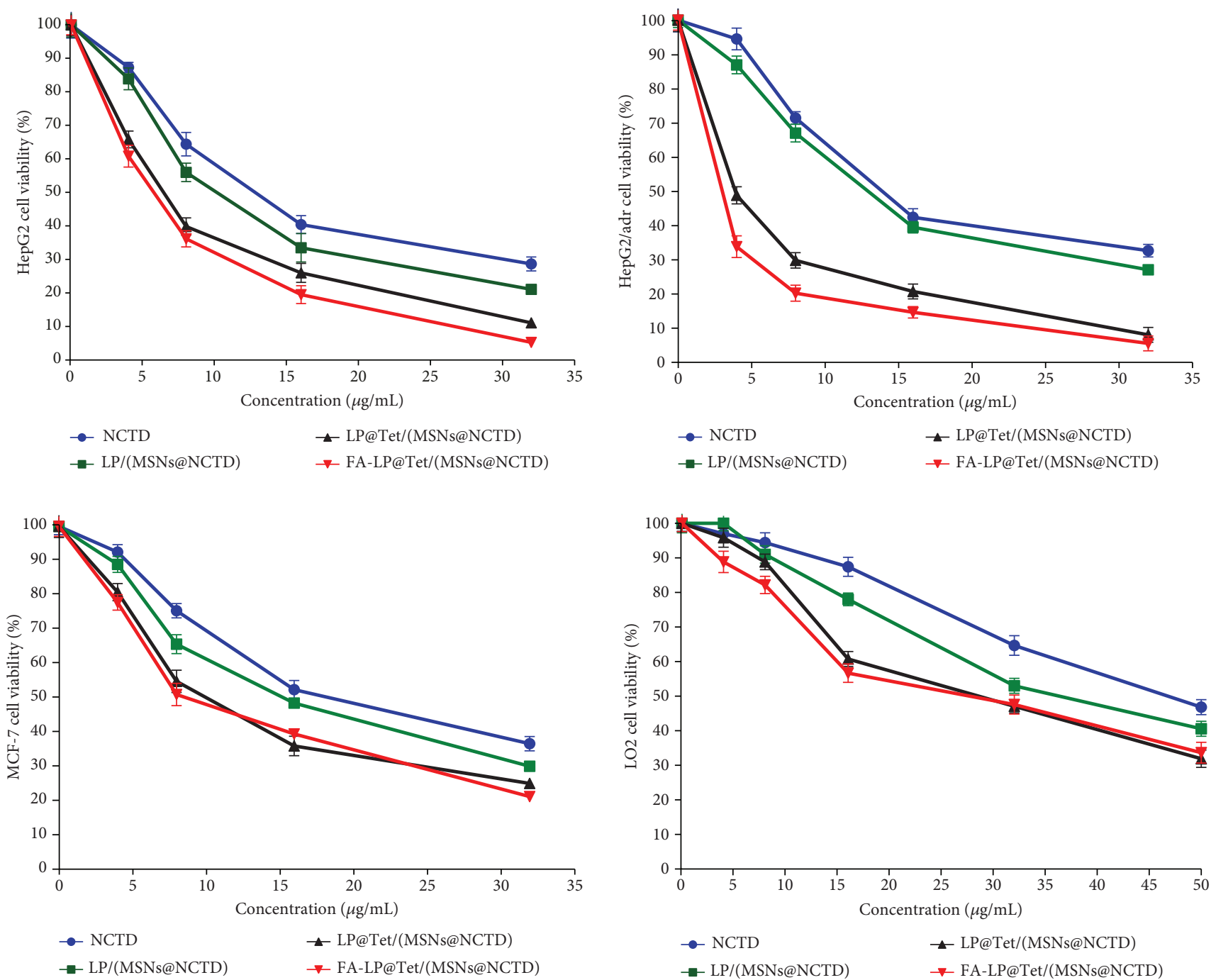

FIgure 12: The viability of HepG2, HepG2/Adr, MCF-7, and LO2 cells after being treated with NCTD, LP/(MSNs@NCTD), LP@Tet/(MSNs@NCTD), and FA-LP@Tet/(MSNs@NCTD) during a certain concentration range $(n=3)$.

FA-LP@Tet/(MSNs@NCTD) induced stronger apoptosis in HepG2/Adr cells than in HepG2 cells.

Cell apoptosis was also determined with flow cytometry. As shown in Figure 15, no significant apoptosis occurred in the control group $(0 \mu \mathrm{g} / \mathrm{mL})$; the survival cell rates of LO2, HepG2, and HepG2/Adr were $93.21 \%$, $97.01 \%$, and $88.34 \%$, respectively. With the increasing concentration of FA-LP@Tet/(MSNs@NCTD) from $8 \mu \mathrm{g} / \mathrm{mL}$ to $16 \mu \mathrm{g} / \mathrm{mL}$, the apoptosis rates of the three cell lines also increased. Thus, the nanoparticles showed a concentration-dependent cytotoxic effect. Apoptosis could be ordered as follows: HepG2/Adr cells > HepG2 cells > LO2 cells. Taken together, the results confirmed that FALP@Tet/(MSNs@NCTD) was suitable for treating hepatic carcinoma.

3.8.FA-LP@Tet/(MSNs@NCTD) Inhibited P-gp Expression. The expression of the P-gp protein in HepG2/Adr cells treated with different formulations is shown in Figure 16. Compared with the control group, FA-LP@Tet/(MSNs@
NCTD) and LP@Tet/(MSNs@NCTD) showed the significant P-gp inhibition which confirmed that the Tet-containing formulations could reverse MDR.

\section{Conclusions}

In this study, NCTD/Tet dual-drug loaded lipid nanoparticles with controlled release and targeted transport characteristics were successfully constructed. The novel liver active-targeting drug delivery system (FALP@Tet/(MSNs@NCTD)) presented a high DL amount and drug EE. The particle size, polydispersity index, and zeta potential of FA-LP@Tet/(MSNs@NCTD) were $153.17 \pm 3.17 \mathrm{~nm}, \quad 0.191 \pm 0.017, \quad$ and $-20.93 \pm 1.75 \mathrm{mV}$, respectively. The prepared nanoparticles had a visible coreshell structure under transmission electron microscopy. The intracellular distribution experiments suggested that FA could enhance the cellular uptake. Cell apoptosis assays showed FA-LP@Tet/(MSNs@NCTD) had good antitumor ability via reversing multidrug resistance. Therefore, FA- 


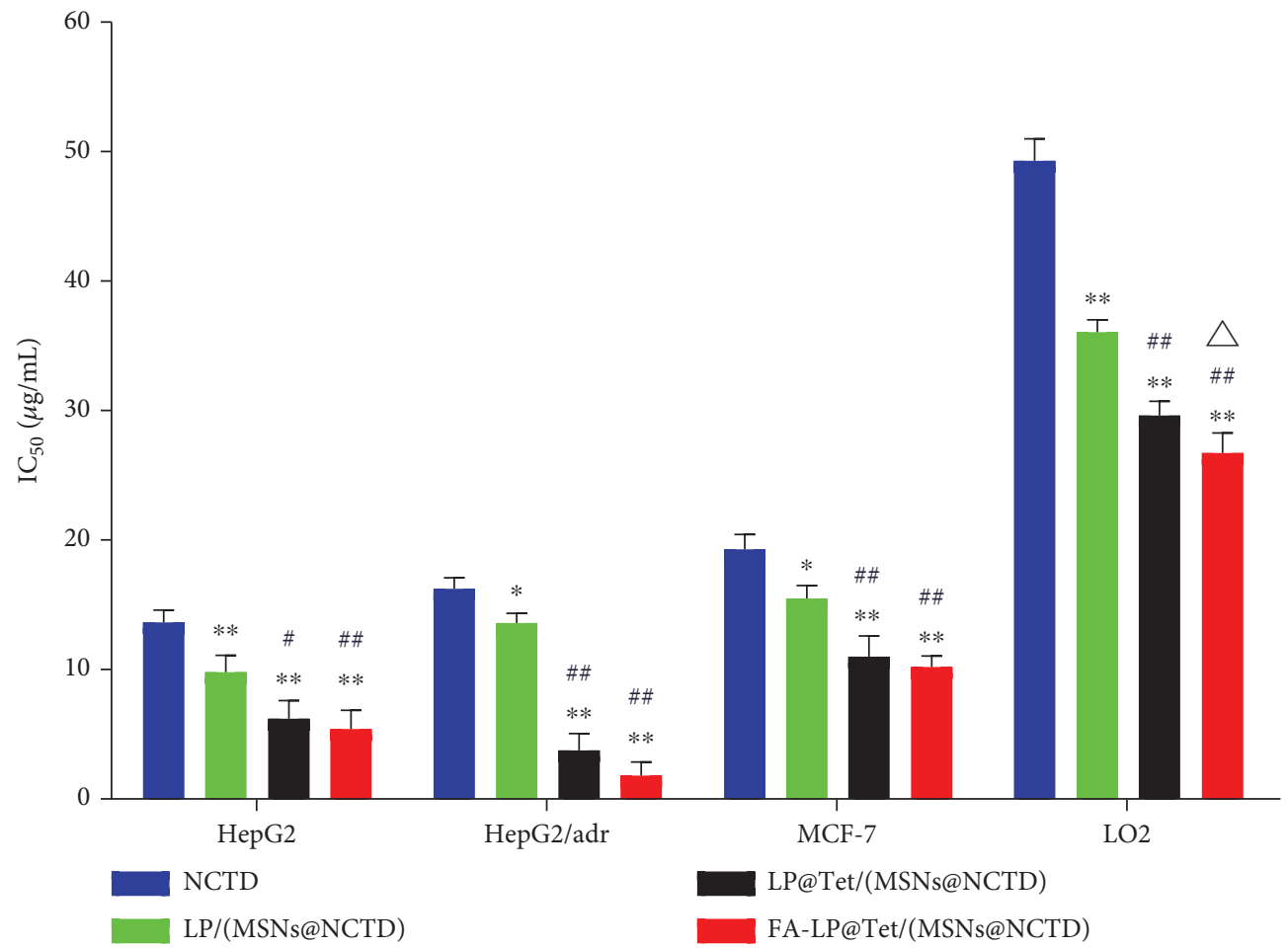

Figure 13: $\mathrm{IC}_{50}$ values $(\mu \mathrm{g} / \mathrm{mL})$ of HepG2, HepG2/Adr, MCF-7, and LO2 cells induced by various formulations. ${ }^{*} P<0.05$ and ${ }^{* *} P<0.01$ vs. the NCTD group; ${ }^{\#} P<0.05$ and ${ }^{\# \#} P<0.01$ vs. the LP/(MSNs@NCTD) group; ${ }^{\triangle} P<0.05$ vs. the LP@Tet/(MSNs@NCTD) group ( $\left.n=3\right)$.

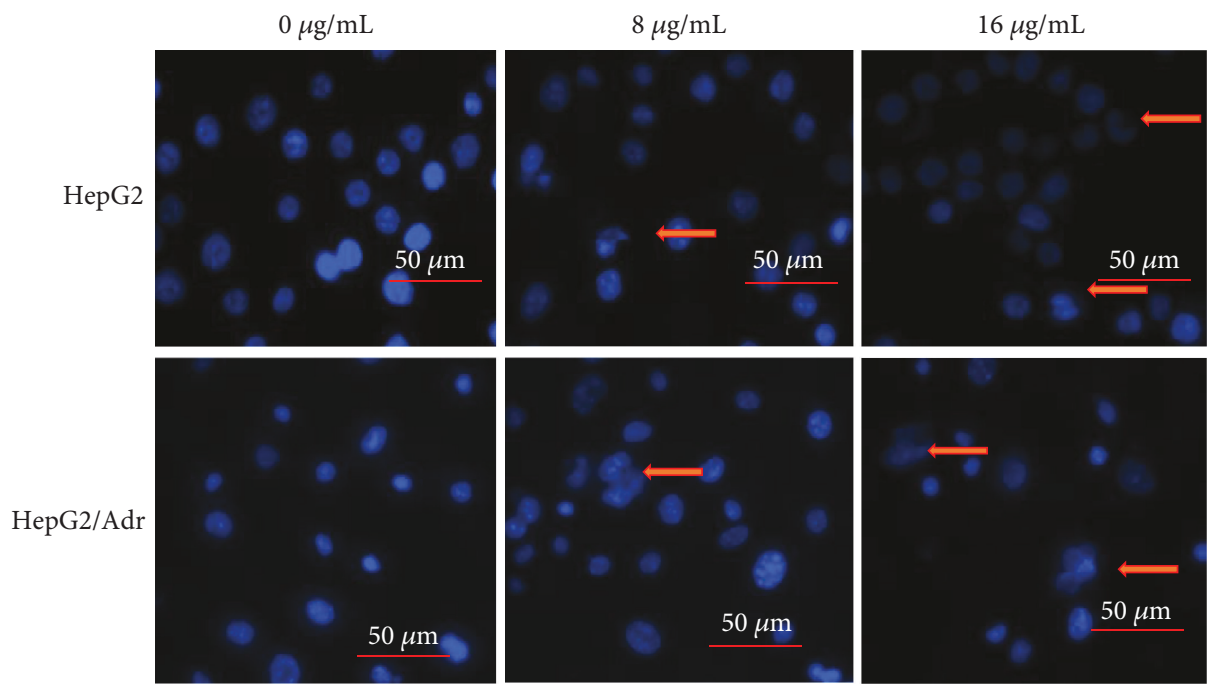

Figure 14: The effect of different concentrations of FA-LP@Tet/(MSNs@NCTD) on HepG2 and HepG2/Adr cell apoptosis, respectively. HepG2 and HepG2/Adr cells were treated with FA-LP@Tet/(MSNs@NCTD) at the concentrations from $0 \mu \mathrm{g} / \mathrm{mL}$ to $16 \mu \mathrm{g} / \mathrm{mL}$ for $24 \mathrm{~h}$ and then stained with DAPI.

LP@Tet/(MSNs@ NCTD) was a promising drug delivery system for combination cancer therapy.

\section{Discussion}

The particle size, dispersity, and zeta potential of nanoparticles are key considerations in the preparation process. A suitable particle size enables adaptation of the administration route (intravenous injection) and passive targeting of the drug delivery system to lesion locations. Particles with diameters less than $200 \mathrm{~nm}$ are able to pass through the fenestrae between endothelial cells and accumulate within tumors. Good dispersity could reduce or eliminate the agglomeration of nanoparticles [28], as nonspecific interactions between positively charged particles and anionic components (such as serum components) could result in their severe aggregation and rapid elimination from the circulation by the reticuloendothelial system [29, 30]. As 

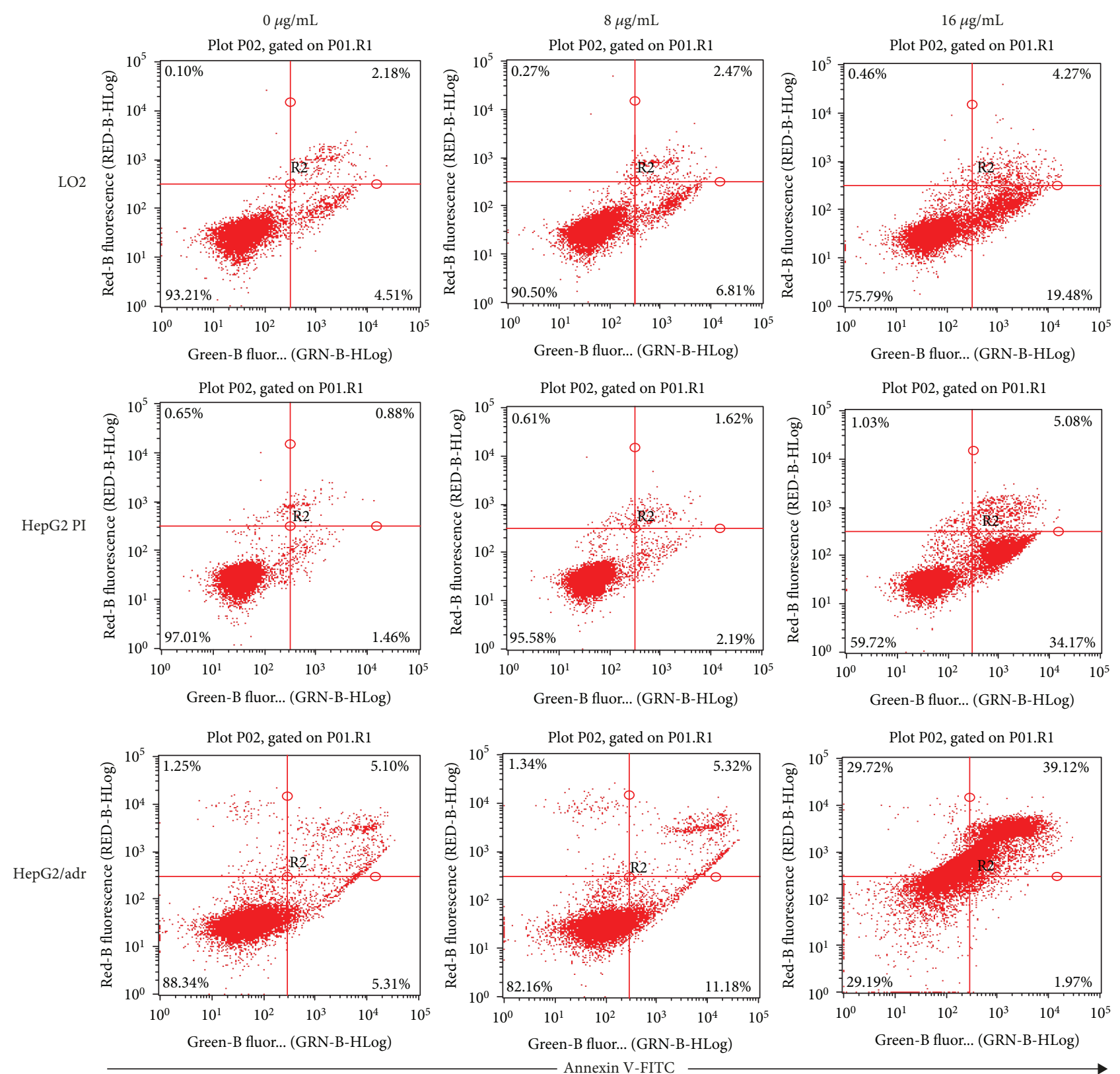

FIGURE 15: The cell apoptosis after the LO2, HepG2, and HepG2/Adr cells treated with FA-LP@Tet/(MSNs@ NCTD) at concentrations from $0 \mu \mathrm{g} / \mathrm{mL}$ to $16 \mu \mathrm{g} / \mathrm{mL}$ for $24 \mathrm{~h}$.

such, the effects of varying ratios of CTAB to TEOS, with or without ethanol, were investigated in our study. The former could affect the mesoporous pore and particle sizes of the MSNs, while the latter could improve the dispersity of MSNs [31].

The cellular uptake results were consistent with the expected objective that modification of FA significantly improves the endocytosis of nanoparticles by its targeting role. A folate receptor is a glycoprotein on the surface of cell membranes with high affinity to FA and overexpresses on the surface of tumor cells $[32,33]$. Thus, FA could deliver formulations to tumor cells and achieve the goal of targeted therapy. The cytotoxicity results showed that LP-MSNs and FA-LP-MSNs have higher safety and lower toxicity than
MSNs, likely because the lipid bilayer could enhance the biocompatibility of drug delivery systems [17, 18]. The large specific surface area of MSNs may destroy the stability of the cell membrane when the particles come into contact with cells [34]. FA-LP@Tet/(MSNs@NCTD) demonstrated the strongest inhibitory activity among the formulations tested, which could be caused by the high accumulation of drugs in tumor cells.

The drug carrier toxicity results indicated that over $80 \%$ of cells survived when the concentration of the drug carriers was below $20 \mu \mathrm{g} / \mathrm{mL}$. Thus, we selected 8 and $16 \mu \mathrm{g} / \mathrm{mL}$ as low and high dosages to perform cell apoptosis assays and Western blot experiments. The cell apoptosis results suggested that the effect of FA-LP@Tet/(MSNs@NCTD)- 


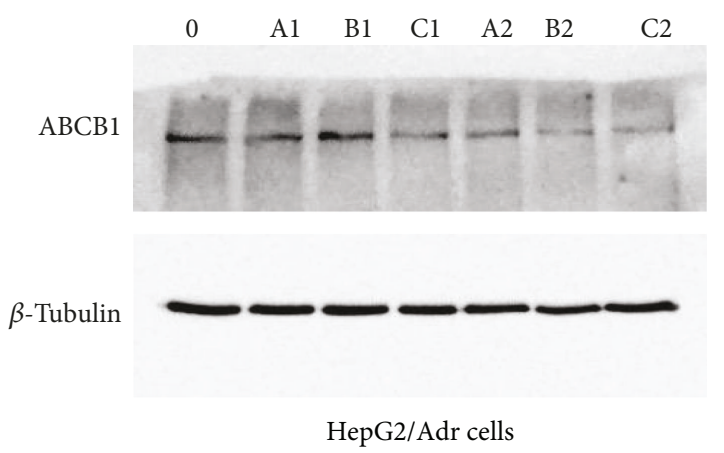

Figure 16: The effects of different formulations on the P-gp expression in HepG2/Adr cells (0: control group; A1-C1: $8 \mu \mathrm{g} / \mathrm{mL}$ of FA-LP@Tet/MSNs, FA-LP/(MSNs@NCTD), and FA-LP@Tet/(MSNs@ NCTD); A2-C2: $16 \mu \mathrm{g} / \mathrm{mL}$ of FALP@Tet/MSNs, FA-LP/(MSNs@NCTD), and FA-LP@Tet/(MSNs@ NCTD)).

induced cell apoptosis exhibited concentration dependence. FA-LP@Tet/(MSNs@NCTD) showed excellent antitumor efficiency, especially in HepG2/Adr cells. The western blot results indicated that Tet could inhibit the expression of the $\mathrm{P}$-gp protein, which was in accordance with a previous literature showing that Tet reversed tumor MDR caused by P-gp overexpression [35]. Therefore, the NCTD/Tet dual-drug loaded lipid nanoparticles could significantly improve the antitumor efficiency of NCTD.

\section{Data Availability}

The data used to support the findings of this study are included within the article.

\section{Conflicts of Interest}

The authors declare that there is no conflict of interest regarding the publication of this paper.

\section{Acknowledgments}

This study was supported by the National Science Foundation of China (Nos. 81473361 and 81703713) and Zhejiang Traditional Chinese Medicine Science and Technology Project (2015ZB038).

\section{References}

[1] R. L. Siegel, K. D. Miller, and A. Jemal, "Cancer statistics, 2018," CA: a Cancer Journal for Clinicians, vol. 68, no. 1, pp. 7-30, 2018.

[2] P. Cotovio, C. Silva, M. Guedes Marques et al., "Acute kidney injury by cantharidin poisoning following a silly bet on an ugly beetle," Clinical Kidney Journal, vol. 6, no. 2, pp. 201-203, 2013.

[3] S. Jiang, M. Li, Y. Hu, Z. Zhang, and H. Lv, "Multifunctional self-assembled micelles of galactosamine-hyaluronic acidvitamin $\mathrm{E}$ succinate for targeting delivery of norcantharidin to hepatic carcinoma," Carbohydrate Polymers, vol. 197, pp. 194-203, 2018.
[4] Y. Y. Bei, X. Y. Chen, Y. Liu et al., "Novel norcantharidinloaded liver targeting chitosan nanoparticles to enhance intestinal absorption," International Journal of Nanomedicine, vol. 7, pp. 1819-1827, 2012.

[5] L. Deng and S. Tang, "Norcantharidin analogues: a patent review (2006 - 2010)," Expert Opinion on Therapeutic Patents, vol. 21, no. 11, pp. 1743-1753, 2011.

[6] Y. Cao, Z. Li, L. Mao et al., "The use of proteomic technologies to study molecular mechanisms of multidrug resistance in cancer," European Journal of Medicinal Chemistry, vol. 162, pp. 423-434, 2019.

[7] N. Li, C. X. Zhang, X. X. Wang et al., "Development of targeting lonidamine liposomes that circumvent drug-resistant cancer by acting on mitochondrial signaling pathways," Biomaterials, vol. 34, no. 13, pp. 3366-3380, 2013.

[8] X. Ma, J. Zhou, C. X. Zhang et al., "Modulation of drugresistant membrane and apoptosis proteins of breast cancer stem cells by targeting berberine liposomes," Biomaterials, vol. 34, no. 18, pp. 4452-4465, 2013.

[9] Y. Lu, F. Li, T. Xu, and J. Sun, “Tetrandrine prevents multidrug resistance in the osteosarcoma cell line, U-2OS, by preventing Pgp overexpression through the inhibition of NF- $\kappa \mathrm{B}$ signaling," International Journal of Molecular Medicine, vol. 39, no. 4, pp. 993-1000, 2017.

[10] X. L. Song, S. Liu, Y. Jiang et al., “Targeting vincristine plus tetrandrine liposomes modified with DSPE-PEG 2000 -transferrin in treatment of brain glioma," European Journal of Pharmaceutical Sciences, vol. 96, pp. 129-140, 2017.

[11] N. Wei, G. T. Liu, X. G. Chen, Q. Liu, F. P. Wang, and H. Sun, "H1, a derivative of Tetrandrine, exerts anti-MDR activity by initiating intrinsic apoptosis pathway and inhibiting the activation of Erk1/2 and Akt1/2," Biochemical Pharmacology, vol. 82, no. 11, pp. 1593-1603, 2011.

[12] J. M. Wu, Y. Chen, J. C. Chen, T. Y. Lin, and S. H. Tseng, "Tetrandrine induces apoptosis and growth suppression of colon cancer cells in mice," Cancer Letters, vol. 287, no. 2, pp. 187-195, 2010.

[13] C. L. Dai, H. Y. Xiong, L. F. Tang et al., "Tetrandrine achieved plasma concentrations capable of reversing MDR in vitro and had no apparent effect on doxorubicin pharmacokinetics in mice," Cancer Chemotherapy and Pharmacology, vol. 60, no. 5, pp. 741-750, 2007.

[14] P. Kumar, P. Tambe, K. M. Paknikar, and V. Gajbhiye, "Mesoporous silica nanoparticles as cutting-edge theranostics: advancement from merely a carrier to tailor-made smart delivery platform," Journal of Controlled Release, vol. 287, pp. 35-57, 2018.

[15] J. Wang, Y. Wang, Q. Liu et al., "Rational design of multifunctional dendritic mesoporous silica nanoparticles to load curcumin and enhance efficacy for breast cancer therapy," ACS Applied Materials \& Interfaces, vol. 8, no. 40, pp. 26511-26523, 2016.

[16] L. Chen, W. Feng, X. Zhou, Z. Yin, and C. He, “Thermo-and $\mathrm{pH}$ dual-responsive mesoporous silica nanoparticles for controlled drug release," Journal of Controlled Release, vol. 213, pp. e69-e70, 2015.

[17] W. Fei, Y. Zhang, S. Han et al., "RGD conjugated liposomehollow silica hybrid nanovehicles for targeted and controlled delivery of arsenic trioxide against hepatic carcinoma," International Journal of Pharmaceutics, vol. 519, no. 1-2, pp. 250$262,2017$. 
[18] Q. Li, W. Li, H. Di et al., “A photosensitive liposome with NIR light triggered doxorubicin release as a combined photodynamic-chemo therapy system," Journal of Controlled Release, vol. 277, pp. 114-125, 2018.

[19] M. Alibolandi, K. Abnous, F. Hadizadeh et al., "Dextran-poly lactide-co-glycolide polymersomes decorated with folateantennae for targeted delivery of docetaxel to breast adenocarcinima in vitro and in vivo," Journal of Controlled Release, vol. 241, pp. 45-56, 2016.

[20] C. W. Chen, Y. C. Chan, M. Hsiao, and R. S. Liu, "Plasmonenhanced photodynamic cancer therapy by upconversion nanoparticles conjugated with Au nanorods," ACS Applied Materials \& Interfaces, vol. 8, no. 47, pp. 32108-32119, 2016.

[21] X. Zhang, F. Li, S. Guo et al., "Biofunctionalized polymer-lipid supported mesoporous silica nanoparticles for release of chemotherapeutics in multidrug resistant cancer cells," Biomaterials, vol. 35, no. 11, pp. 3650-3665, 2014.

[22] Y. Lu, S. Han, H. Zheng et al., "A novel RGDyC/PEG comodified PAMAM dendrimer-loaded arsenic trioxide of glioma targeting delivery system," International Journal of Nanomedicine, vol. 13, pp. 5937-5952, 2018.

[23] Q. Zhao, H. Geng, Y. Wang et al., "Hyaluronic acid oligosaccharide modified redox-responsive mesoporous silica nanoparticles for targeted drug delivery," ACS Applied Materials \& Interfaces, vol. 6, no. 22, pp. 20290-20299, 2014.

[24] M. Guan, Y. Zhou, Q. L. Zhu et al., "N-Trimethyl chitosan nanoparticle-encapsulated lactosyl-norcantharidin for liver cancer therapy with high targeting efficacy," Nanomedicine: Nanotechnology, Biology and Medicine, vol. 8, no. 7, pp. 1172-1181, 2012.

[25] X. Wang, Z. Feng, J. Li, L. Chen, and W. Tang, "High glucose induces autophagy of MC3T3-E1 cells via ROS-AKT-mTOR axis," Molecular and Cellular Endocrinology, vol. 429, pp. 62-72, 2016.

[26] Q. Wu, Y. Hou, G. Han et al., "Mixed shell mesoporous silica nanoparticles for controlled drug encapsulation and delivery," Nanomedicine, vol. 12, no. 22, pp. 2699-2711, 2017.

[27] W. Song, D. Y. Shen, J. H. Kang et al., “Apoptosis of human cholangiocarcinoma cells induced by ESC-3 from Crocodylus siamensis bile," World Journal of Gastroenterology, vol. 18, no. 7, pp. 704-711, 2012.

[28] C. Sauter, M. A. Emin, H. P. Schuchmann, and S. Tavman, "Influence of hydrostatic pressure and sound amplitude on the ultrasound induced dispersion and de-agglomeration of nanoparticles," Ultrasonics Sonochemistry, vol. 15, no. 4, pp. 517-523, 2008.

[29] J. Li, X. Yu, Y. Wang et al., "A reduction and $\mathrm{pH}$ dual-sensitive polymeric vector for long-circulating and tumor-targeted siRNA delivery," Advanced Materials, vol. 26, no. 48, pp. 8217-8224, 2014.

[30] X. Z. Yang, J. Z. Du, S. Dou, C. Q. Mao, H. Y. Long, and J. Wang, "Sheddable ternary nanoparticles for tumor acidity-targeted sirna delivery," ACS Nano, vol. 6, no. 1, pp. 771-781, 2011.

[31] A. S. Timin, E. V. Balantseva, S. Y. Khashirova, E. V. Rumyantsev, and T. Y. Osadchaya, "Application of guanidine-containing polymers for preparation of $\mathrm{pH}$ responsive silica-based particles for drug delivery systems," Colloids and Surfaces A: Physicochemical and Engineering Aspects, vol. 477, pp. 26-34, 2015.
[32] D. Feng, Y. Song, W. Shi, X. Li, and H. Ma, "Distinguishing folate-receptor-positive cells from folate-receptor-negative cells using a fluorescence off-on nanoprobe," Analytical Chemistry, vol. 85, no. 13, pp. 6530-6535, 2013.

[33] J. M. Liu, J. T. Chen, and X. P. Yan, "Near infrared fluorescent trypsin stabilized gold nanoclusters as surface plasmon enhanced energy transfer biosensor and in vivo cancer imaging bioprobe," Analytical Chemistry, vol. 85, no. 6, pp. 3238-3245, 2013.

[34] J. L. Vivero-Escoto, I. I. Slowing, and V. S. Y. Lin, “Tuning the cellular uptake and cytotoxicity properties of oligonucleotide intercalator-functionalized mesoporous silica nanoparticles with human cervical cancer cells HeLa," Biomaterials, vol. 31, no. 6, pp. 1325-1333, 2010.

[35] Y. F. Sun and M. Wink, "Tetrandrine and fangchinoline, bisbenzylisoquinoline alkaloids from Stephania tetrandra can reverse multidrug resistance by inhibiting P-glycoprotein activity in multidrug resistant human cancer cells," Phytomedicine, vol. 21, no. 8-9, pp. 1110-1119, 2014. 


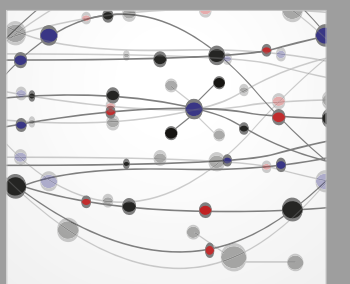

The Scientific World Journal
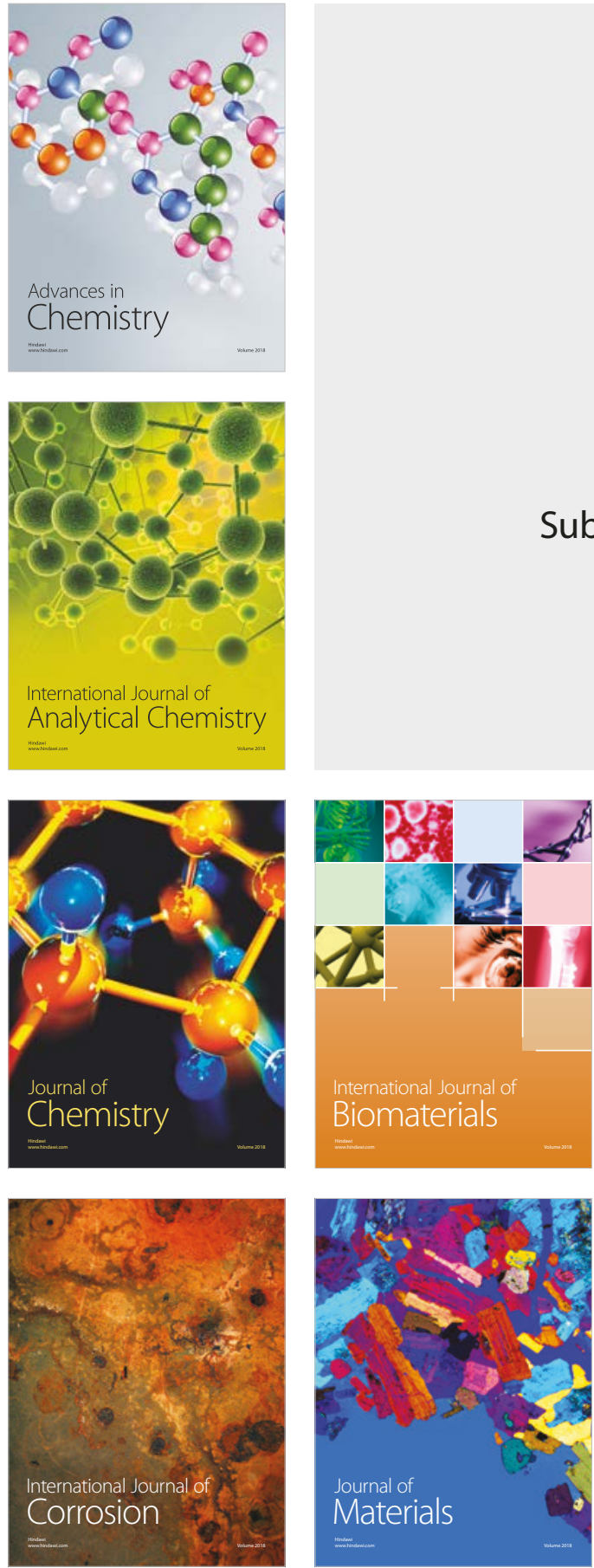

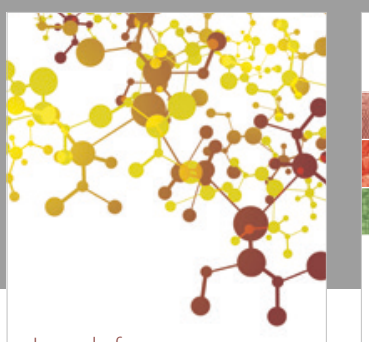

Journal of

Applied Chemistry
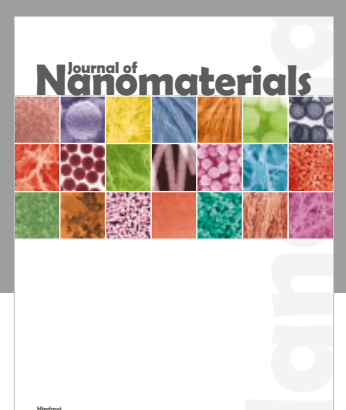

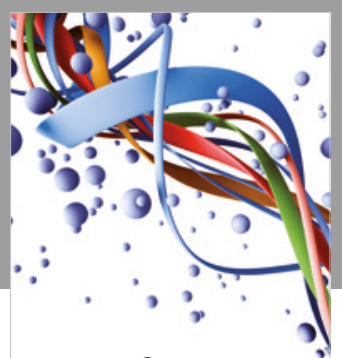

Scientifica

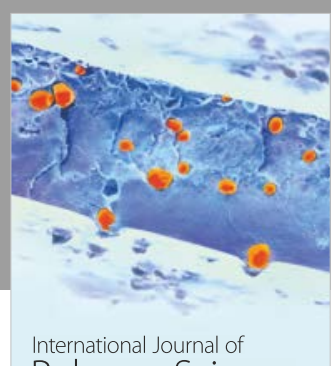

Polymer Science

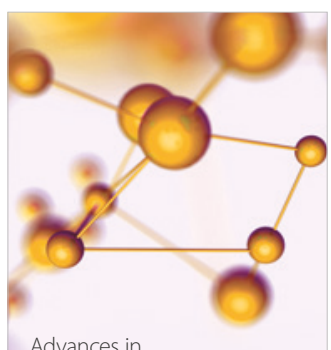

Physical Chemistry
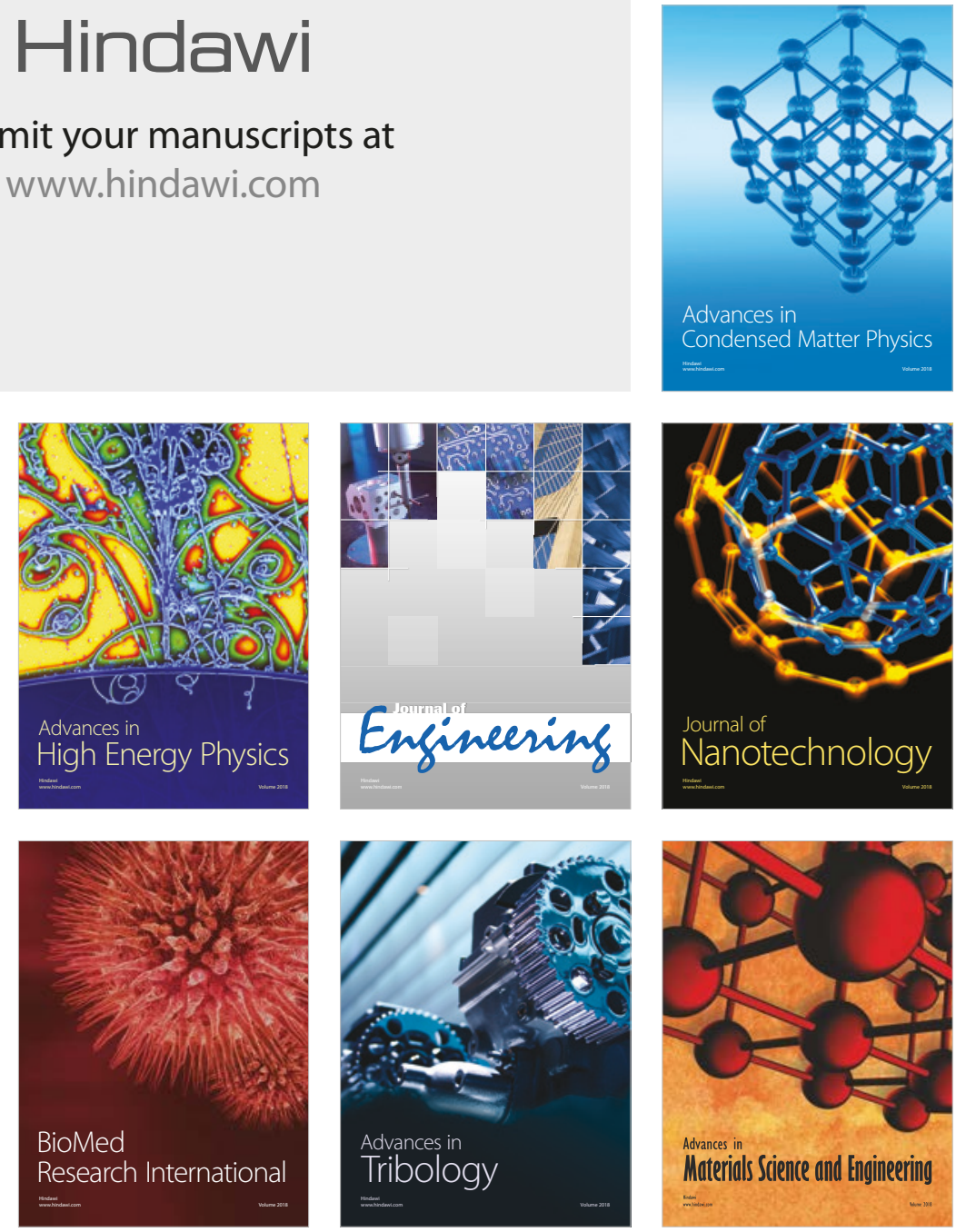